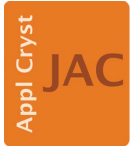

JOURNAL OF

APPLIED

CRYSTALLOGRAPHY

ISSN 1600-5767

Received 15 September 2015

Accepted 7 March 2016

Edited by Th. Proffen, Oak Ridge National Laboratory, USA

Keywords: calcium silicate hydrates; $\mathrm{C}-\mathrm{S}-\mathrm{H}$; $\mathrm{X}$-ray diffraction; ${ }^{29} \mathrm{Si} \mathrm{NMR}$; synchrotron X-ray absorption.

Supporting information: this article has supporting information at journals.iucr.org/j

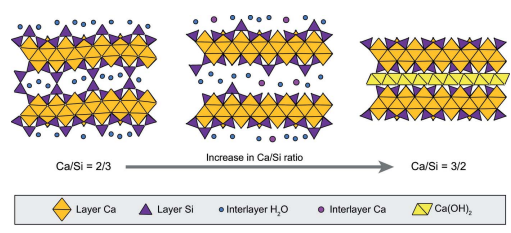

OPEN $\odot$ ACCESS

\section{Structure of nanocrystalline calcium silicate hydrates: insights from X-ray diffraction, synchrotron X-ray absorption and nuclear magnetic resonance}

\author{
Sylvain Grangeon, ${ }^{\mathrm{a} *}$ Francis Claret, ${ }^{\mathrm{a}}$ Cédric Roosz, ${ }^{\mathrm{a}, \mathrm{b}}$ Tsutomu Sato, ${ }^{\mathrm{c}}$ Stéphane \\ Gaboreau $^{a}$ and Yannick Linard ${ }^{d}$
}

${ }^{a}$ D3E/SVP, BRGM (French Geological Survey), 3 avenue Claude Guillemin, Orléans, 45060, France, ${ }^{\mathbf{b}}$ Scientific Division, Andra, 1-7 rue Jean Monnet, Parc de la Croix Blanche, Châtenay-Malabry, France, 'Laboratory of Environmental Geology, Research Group of Geoenvironmental/Engineering Division of Solid Waste, Resources and Geoenvironmental/ Engineering Graduate School of Engineering, Hokkaido University, Kita 13 Nishi 8, Sapporo, Japan, and ${ }^{\mathbf{d} C e n t r e ~ d e}$ Meuse/Haute Marne, Andra, Bure, 55290, France. *Correspondence e-mail: s.grangeon@brgm.fr

The structure of nanocrystalline calcium silicate hydrates $(\mathrm{C}-\mathrm{S}-\mathrm{H})$ having $\mathrm{Ca} / \mathrm{Si}$ ratios ranging between $0.57 \pm 0.05$ and $1.47 \pm 0.04$ was studied using an electron probe micro-analyser, powder $\mathrm{X}$-ray diffraction, ${ }^{29} \mathrm{Si}$ magic angle spinning NMR, and Fourier-transform infrared and synchrotron X-ray absorption spectroscopies. All samples can be described as nanocrystalline and defective tobermorite. At low $\mathrm{Ca} / \mathrm{Si}$ ratio, the Si chains are defect free and the $\mathrm{Si} Q^{3}$ and $Q^{2}$ environments account, respectively, for up to $40.2 \pm 1.5 \%$ and $55.6 \pm 3.0 \%$ of the total $\mathrm{Si}$, with part of the $Q^{3} \mathrm{Si}$ being attributable to remnants of the synthesis reactant. As the $\mathrm{Ca} / \mathrm{Si}$ ratio increases up to $0.87 \pm 0.02$, the $\mathrm{Si} Q^{3}$ environment decreases down to 0 and is preferentially replaced by the $Q^{2}$ environment, which reaches $87.9 \pm 2.0 \%$. At higher ratios, $Q^{2}$ decreases down to $32.0 \pm 7.6 \%$ for Ca/ $\mathrm{Si}=1.38 \pm 0.03$ and is replaced by the $Q^{1}$ environment, which peaks at $68.1 \pm$ $3.8 \%$. The combination of X-ray diffraction and NMR allowed capturing the depolymerization of Si chains as well as a two-step variation in the layer-to-layer distance. This latter first increases from $\sim 11.3 \AA$ (for samples having a $\mathrm{Ca} / \mathrm{Si}$ ratio $<\sim 0.6$ ) up to $12.25 \AA$ at $\mathrm{Ca} / \mathrm{Si}=0.87 \pm 0.02$, probably as a result of a weaker layer-to-layer connectivity, and then decreases down to $11 \AA$ when the $\mathrm{Ca} / \mathrm{Si}$ ratio reaches $1.38 \pm 0.03$. The decrease in layer-to-layer distance results from the incorporation of interlayer $\mathrm{Ca}$ that may form a $\mathrm{Ca}(\mathrm{OH})_{2}$-like structure, nanocrystalline and intermixed with $\mathrm{C}-\mathrm{S}-\mathrm{H}$ layers, at high $\mathrm{Ca} / \mathrm{Si}$ ratios.

\section{Introduction}

Nanocrystalline calcium silicate hydrate $(\mathrm{C}-\mathrm{S}-\mathrm{H})$ is a synthetic phase forming the main hydration product of many types of cements (Richardson, 1999, 2008), including ordinary Portland cement. It has a complex chemistry, which manifests itself by the variability of its calcium to silicon $(\mathrm{Ca} / \mathrm{Si})$ atomic ratio, generally reported to vary between $\sim 0.6$ and $\sim 2.4$ (Richardson, 1999), and by its capacity to incorporate foreign elements such as aluminium or sodium (e.g. Bach et al., 2013; Faucon et al., 1998, 1999; Pardal et al., 2012). C-S-H is ubiquitous in building materials, where it controls the main cement chemical (Blanc et al., 2010) and mechanical (Manzano et al., 2007; Pellenq et al., 2009) properties. C-S-H has been the subject of many studies that aimed to build structure models which can be used to understand $\mathrm{C}-\mathrm{S}-\mathrm{H}$ mechanical properties (Abdolhosseini Qomi et al., 2014) and for chemical thermodynamic modelling (Myers et al., 2013, 2014; Walker et al., 2007). However, the determination of the 
structure of C-S-H has long been hampered by the fact that it is nanocrystalline, has disordered structure (Grangeon, Claret, Linard \& Chiaberge, 2013; Skinner et al., 2010; Soyer-Uzun et al., 2012) and is often intermixed with $\mathrm{Ca}(\mathrm{OH})_{2}$ which may be structurally bound (Chen et al., 2010). These characteristics, together with the use of several different methods of analysis by different research groups, have led to the development of numerous structural models, with two of them being dominant. In the first model, the evolution of the $\mathrm{C}-\mathrm{S}-\mathrm{H}$ structure as a function of its $\mathrm{Ca} / \mathrm{Si}$ ratio is described by the existence of two phases having crystal structures close either to tobermorite or to jennite (Richardson, 2008; Taylor, 1986), depending on the $\mathrm{Ca} / \mathrm{Si}$ ratio. The former is assumed to be analogous to $\mathrm{C}-\mathrm{S}-\mathrm{H}$ for $\mathrm{Ca} / \mathrm{Si}$ ratios lower than $\sim 1.3$ and the latter is assumed to be analogous to $\mathrm{C}-\mathrm{S}-\mathrm{H}$ for higher $\mathrm{Ca} / \mathrm{Si}$ ratios. These two minerals are layered structures built of $\mathrm{Ca}$ polyhedra (in sevenfold coordination in tobermorite, sixfold in jennite) with ribbons of wollastonite-like Si chains running at the surface. In both cases, the layers are separated by a hydrated interlayer space that may contain cations. In the alternative model, the whole range of $\mathrm{Ca} / \mathrm{Si}$ is described using tobermorite and a varying amount of calcium hydroxide $(\mathrm{CH})$, which may be structurally bound to the tobermorite layers (Richardson, 2008, 2014). C-S-H and $\mathrm{CH}$ form a nanocomposite (i.e. intimate mix of the two phases), with $\mathrm{CH}$ filling the micropores in the $\mathrm{C}-\mathrm{S}-\mathrm{H}$ structure, possibly through interstratification of C-S-H and $\mathrm{CH}$ layers (Girão et al., 2010; Grangeon, Claret, Linard \& Chiaberge, 2013; Richardson, 2014 ), when the $\mathrm{Ca} / \mathrm{Si}$ ratio approaches $\sim 1.5$. At higher $\mathrm{Ca} / \mathrm{Si}$, $\mathrm{C}-\mathrm{S}-\mathrm{H}$ and $\mathrm{CH}$ form a microcomposite, with $\mathrm{CH}$ precipitating outside C-S-H micropores (Chen et al., 2010), as supported by the frequent observation of a discrete $\mathrm{CH}$ phase (portlandite) in X-ray diffraction patterns of $\mathrm{C}-\mathrm{S}-\mathrm{H}$ having a $\mathrm{Ca} / \mathrm{Si}$ ratio higher than 1.5 (Garbev, Beuchle et al., 2008; Renaudin et al., 2009). The tobermorite-like model explains electrophoretic measurements made on $\mathrm{C}-\mathrm{S}-\mathrm{H}$ suspensions (Churakov et al., 2014) and aluminium uptake by C-S-H (e.g. Andersen et al., 2003; Myers et al., 2013, 2015; Pardal et al., 2012; Pegado et al., 2014). It is also in agreement with recent developments made in thermodynamic modelling (e.g. Myers et al., 2014; Richardson, 2008; Walker et al., 2007). A sketch of the C-S-H structure under the tobermorite-like assumption is shown in Fig. 1.

As indicated above, the ambiguities that remain as to which structure model most accurately describes $\mathrm{C}-\mathrm{S}-\mathrm{H}$ evolution as a function of its $\mathrm{Ca} / \mathrm{Si}$ ratio mainly result from the intense structural disorder reigning in this phase, with additional complexity arising from nanocrystallinity. Disorder occurs first in the arrangement between $\mathrm{C}-\mathrm{S}-\mathrm{H}$ particles (Etzold et al., 2014; Feldman \& Sereda, 1968) but also and more importantly within the $\mathrm{C}-\mathrm{S}-\mathrm{H}$ crystals themselves. As a consequence of this disorder, X-ray diffraction patterns exhibit a few broad and, for some of them, asymmetric maxima. As this cannot be straightforwardly taken into account in the Rietveld X-ray diffraction (XRD) refinement method, it led to the use of alternative methods which probe the local or medium-range order in the $\mathrm{C}-\mathrm{S}-\mathrm{H}$ structure (e.g. ${ }^{29} \mathrm{Si} \mathrm{NMR}$, infrared and
Raman spectrometries, etc.; Cong \& Kirkpatrick, 1996a,b; Kirkpatrick et al., 1997; Lequeux et al., 1999; Yu et al., 1999). Amongst them, ${ }^{29} \mathrm{Si}$ NMR was proven particularly efficient and helped to demonstrate that the length of the Si chains decreases with increasing $\mathrm{Ca} / \mathrm{Si}$ ratio (e.g. Brunet et al., 2004; Cong \& Kirkpatrick, 1996b). However, this method only provides a partial picture of the structure probed, which induces difficulties of analysis. For example, it may be difficult to distinguish between the Si local environment of jennite-like and $14 \AA$ tobermorite-like structures (Cong \& Kirkpatrick, 1996a). To circumvent such ambiguities, transmission electron microscopy (TEM) has often been used as an alternative method of analysis, as chemical and morphological data can successfully be retrieved at the crystal scale (Groves et al., 1986; Richardson et al., 1994; Richardson \& Groves, 1992b, 1993). TEM is also sometimes used to extract structural information by acquiring electron diffraction patterns and interference fringes, which are compared with those of tobermorite and jennite (Viehland et al., 1996; Zhang et al., 2000). However, in the case of nanocrystalline and lamellar structures, numerous structural particularities, such as internal strains, bending, aggregation or limited stability under the beam, induce many modulations of the diffraction pattern and may lead to incorrect data interpretation (Chatterji, 1997).

Recently, it has been proposed that C-S-H X-ray diffraction patterns could be reproduced by considering that $\mathrm{C}-\mathrm{S}-\mathrm{H}$

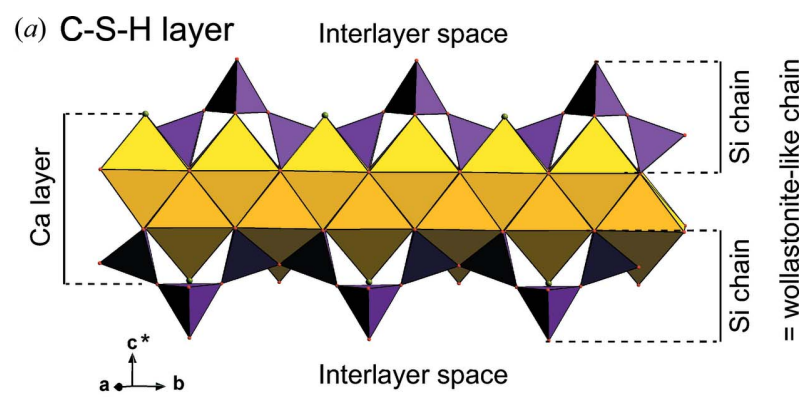

(b) Si sites detected in the present study

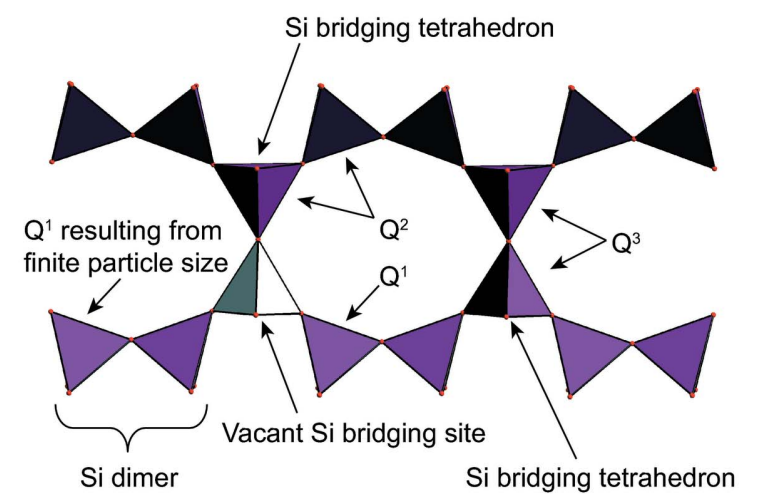

Figure 1

Sketch of the structure of C-S-H, in the tobermorite-like assumption. (a) is a view of the layer, with yellow and purple polyhedra representing, respectively, layer $\mathrm{Ca}$ and layer $\mathrm{Si}$ coordination spheres. The ribbons of $\mathrm{Si}$ tetrahedra, parallel to $\mathbf{b}$, are termed the wollastonite-like chains. They are detailed in $(b)$, where all Si and vacant sites identified in the present study are assigned (see text for details). 
has a tobermorite-like structure affected by turbostratism (the systematic presence, between adjacent layers that remain parallel, of a random rotation and/or a random translation; Grangeon, Claret, Linard \& Chiaberge, 2013). In this model, most of the diffraction maxima are $h k$ bands, whose position, relative intensity and breadth can be exploited to retrieve quantitative data on, for example, the layer structure. Complementary information can be obtained from the study of the 001 reflection [using the indexing proposed by Grangeon, Claret, Lerouge et al. (2013)]. It has been regularly shown that this reflection shifts towards low $d$ spacing with increasing $\mathrm{Ca} / \mathrm{Si}$ ratio (Garbev, Beuchle et al., 2008; Garbev, Bornefeld et al., 2008; Grangeon, Claret, Linard \& Chiaberge, 2013; Matsuyama \& Young, 2000; Renaudin et al., 2009; Richardson, 2014; Walker et al., 2007). This may result from different phenomena, including (i) a change in the layer-tolayer distance, (ii) a change in crystallite size along $\mathbf{c}^{*}$ (i.e. a change in the mean number of layers stacked parallel to each other), and (iii) interstratification, possibly following a random (R0) junction type (Drits \& Tchoubar, 1990; Heller \& Taylor, 1956; Taylor \& Howison, 1956), of different types of layers, including different tobermorite-like layers and (or) $\mathrm{Ca}(\mathrm{OH})_{2}$ layers (Brunauer \& Greenberg, 1960; Girão et al., 2010; Grangeon, Claret, Linard \& Chiaberge, 2013; Heller \& Taylor, 1956; Taylor \& Howison, 1956).

The present study aims to contribute to a better understanding of C-S-H structure. Synchrotron X-ray absorption near-edge structure spectroscopy (XANES) was used to identify the most relevant crystalline analogues of $\mathrm{C}-\mathrm{S}-\mathrm{H}$ and to check for the presence of accessory phases, Fourier-transform infrared (FTIR) spectroscopy to check for the presence of $\left(\mathrm{CO}_{3}\right)^{2-}$ groups that would be indicative of alteration of the samples by atmospheric $\mathrm{CO}_{2},{ }^{29} \mathrm{Si}$ NMR to probe the connectivity of Si atoms, and powder X-ray diffraction (XRD) to probe crystallite sizes, to obtain the layer-to-layer distance and to cross-check the ${ }^{29} \mathrm{Si} \mathrm{NMR}$ results. All of the results are gathered to propose a model for the structural evolution of $\mathrm{C}-$ $\mathrm{S}-\mathrm{H}$ as a function of its $\mathrm{Ca} / \mathrm{Si}$ ratio.

\section{Materials and methods}

\subsection{Samples}

C-S-H samples were synthesized by mixing different molar ratios of $\mathrm{Ca}(\mathrm{OH})_{2}$ (Kanto Chemical, special grade) and amorphous $\mathrm{SiO}_{2}$ (Aerosil200) in a glove-box (under $\mathrm{N}_{2}$ atmosphere) and in $\mathrm{CO}_{2}$-free de-ionized water (Table 1). The target atomic $\mathrm{Ca} / \mathrm{Si}$ ratios were $0.6,0.83,1.0,1.4$ and 1.5. The effect of temperature was investigated by performing syntheses at room temperature (RT), $323 \mathrm{~K}, 353 \mathrm{~K}$ and $443 \mathrm{~K}$ (using an autoclave). All suspensions were stirred during synthesis. Samples are labelled CSH $X-Y \mathrm{~K}$, where $X$ is the target $\mathrm{Ca} / \mathrm{Si}$ ratio and $Y$ the synthesis temperature. The chemical composition of all samples is reported in Table 1. The same protocol, but at a temperature of $453 \mathrm{~K}$ and a pressure of $10^{3} \mathrm{~Pa}$, was applied for synthesizing tobermorite. This synthetic tobermorite, whose $\mathrm{Ca} / \mathrm{Si}$ ratio is $0.82 \pm 0.02$, has a lath-like shape
Table 1

Sample synthesis temperature, and target and actual $\mathrm{Ca} / \mathrm{Si}$ ratios.

\begin{tabular}{|c|c|c|c|c|}
\hline Sample & $\begin{array}{l}\text { Target } \mathrm{Ca} / \mathrm{Si} \\
\left(\text { atom atom }{ }^{-1}\right)\end{array}$ & $\begin{array}{l}\text { Synthesis } \\
\text { temperature (K) }\end{array}$ & $\begin{array}{l}\mathrm{Ca} / \mathrm{Si} \text { ratio } \\
\left(\text { atom }^{-1} \text { atom }^{-1}\right)\end{array}$ & \\
\hline CSH $0.6-323 \mathrm{~K}$ & 0.6 & 323 & $0.57 \pm 0.05$ & 59 \\
\hline CSH $0.6-443 \mathrm{~K}$ & 0.6 & 443 & $0.61 \pm 0.02$ & 50 \\
\hline CSH $0.83-\mathrm{RT}$ & 0.83 & Room temperature & $0.84 \pm 0.03$ & 48 \\
\hline CSH $0.83-323 \mathrm{~K}$ & 0.83 & 323 & $0.87 \pm 0.02$ & 47 \\
\hline CSH $0.83-353 \mathrm{~K}$ & 0.83 & 353 & $0.86 \pm 0.01$ & 50 \\
\hline CSH $0.83-443 \mathrm{~K}$ & 0.83 & 443 & $0.84 \pm 0.02$ & 49 \\
\hline CSH $1.0-323 \mathrm{~K}$ & 1 & 323 & $1.04 \pm 0.03$ & 59 \\
\hline CSH $1.0-443 \mathrm{~K}$ & 1 & 443 & $1.04 \pm 0.05 \ddagger$ & 1 \\
\hline CSH $1.4-323 \mathrm{~K}$ & 1.4 & 323 & $1.38 \pm 0.03$ & 60 \\
\hline CSH $1.5-443 \mathrm{~K}$ & 1.5 & 443 & $1.47 \pm 0.04$ & 60 \\
\hline
\end{tabular}

$\dagger$ Number of independent EPMA analyses. $\ddagger$ Determined using X-ray fluorescence using an aliquot of the bulk sample. Uncertainty is estimated from measurement reproducibility.

with typical dimensions of $1-2 \times 0.1-0.5 \mu \mathrm{m}$ (see supporting information).

After synthesis, all samples were filtrated, freeze-dried and finally left in closed containers in the glove-box until analysis. Note that, despite all precautions taken, samples may have been in contact with minor amounts of water present in the glove-box atmosphere, which may have a minor influence on their structure (adsorption of water on external and interlayer surfaces; e.g. Korpa \& Trettin, 2006; Taylor, 1986; Taylor \& Howison, 1956).

In addition to these synthetic products, synthetic calcite $\left(\mathrm{CaCO}_{3}\right)$ and portlandite $\left[\mathrm{Ca}(\mathrm{OH})_{2}\right]$, as well as natural dolomite $\left(\mathrm{Ca}_{0.5} \mathrm{Mg}_{0.5} \mathrm{CO}_{3}\right.$ from Brumado, Brazil), ettringite $\left[\mathrm{Ca}_{6} \mathrm{Al}_{2}\left(\mathrm{SO}_{4}\right)_{3}(\mathrm{OH})_{12} \cdot 26 \mathrm{H}_{2} \mathrm{O}\right.$; N'Chwaning, South Africa] and gypsum $\left(\mathrm{CaSO}_{4} \cdot 2 \mathrm{H}_{2} \mathrm{O}\right.$; Miyazaki, Japan), were selected to serve as references.

\subsection{Electron probe micro-analysis}

Electron probe micro-analysis (EPMA) of natural and synthetic $\mathrm{C}-\mathrm{S}-\mathrm{H}$ was performed on polished thin sections, made from pressed sample pellets, using a Cameca SX50 electron microprobe (acceleration voltage of $15 \mathrm{kV}$, current beam of $12 \mathrm{nA}$ ) and a 1-2 $\mu \mathrm{m}$ beam width. Prior to analysis, a 10-20 nm-thick carbon layer was sputter-coated onto the samples (Edwards Auto 306). $\mathrm{Ca}$ and $\mathrm{Si}$ were analysed simultaneously. Ca $K \alpha$ and Si $K \alpha$ were analysed using a pentaerythritol crystal and a thallium acid phthalate crystal, respectively. The standards used were albite $\left(\mathrm{NaAlSi}_{3} \mathrm{O}_{8}\right)$ for $\mathrm{Si}$ and wollastonite $\left(\mathrm{CaSiO}_{3}\right)$ for $\mathrm{Ca}$. A ZAF data correction was applied to the raw data.

\subsection{Synchrotron X-ray absorption near-edge structure spectroscopy}

Ca $K$-edge absorption spectra were measured at beamlines 9A and 12C of the Photon Factory, KEK, Tsukuba, Japan (Nomura \& Koyama, 2001). Spectra were recorded in fluorescence mode using a Lytle type detector. Synchrotron radiation from the $2.5 \mathrm{GeV}$ storage ring was monochromated with $\mathrm{Si}(111)$ crystals. The incident beam was collimated to $1 \times$ 
$1 \mathrm{~mm}$. The energy was calibrated by using a $\mathrm{Cu}$ foil and calibrating the pre-edge peak at $8980 \mathrm{eV}$. Data reduction was performed following previous studies (Isaure et al., 2002) and using software from the Advanced Light Source (Berkeley, USA) 10.3.2 beamline (Marcus et al., 2004). Samples were protected from the atmosphere during measurement by using tape.

\subsection{Fourier-transform infrared spectrometry}

FTIR spectra were obtained on a JASCO-FT/IR-4100 spectrometer. For each sample, $1 \mathrm{mg}$ of powder was mixed with $100 \mathrm{mg}$ of $\mathrm{KBr}$ and pressed to produce a pellet. Thirtytwo transmission scans were performed in the $4000-350 \mathrm{~cm}^{-1}$ spectral range with a resolution of $0.024 \mathrm{~cm}^{-1}$ and averaged for each spectrum. The spectrum of CSH $0.6-323 \mathrm{~K}$ could only be recorded in the $3000-350 \mathrm{~cm}^{-1}$ range.

\section{5. ${ }^{29} \mathrm{Si}$ magic angle spinning (MAS) nuclear magnetic} resonance

${ }^{29}$ Si NMR spectra were recorded on a Bruker AVANCE $7.4 \mathrm{~T}$ operated at $59 \mathrm{MHz}$ and equipped with a $4 \mathrm{~mm}$ double bearing MAS probe head spinning at $12 \mathrm{kHz}$. About 16000 scans were accumulated after a $45^{\circ}$ pulse, using a 10 s recycling delay. This delay was optimized to ensure a complete relaxation of the magnetization. ${ }^{29} \mathrm{Si}$ chemical shifts were reported relative to tetramethylsilane resonance. The spectra were simulated as a sum of individual Gaussian-Lorentzian functions, using the Dmfit program (Massiot et al., 2002). Their integrated intensities were used to estimate the amount of the differently coordinated species. The mean Si chain length (i.e. the mean number of $\mathrm{Si}$ atoms that are connected in a chain) was calculated following Richardson (2014).

\subsection{Powder X-ray diffraction}

XRD was performed with a Rigaku RINT-2000, operated at $30 \mathrm{kV}$ and $20 \mathrm{~mA}$, using $\mathrm{Cu} K \alpha$ radiation $(\lambda=1.5418 \AA)$, a divergence slit of $1^{\circ}$, a scatter slit of $1^{\circ}$ and a receiving slit of $3 \mathrm{~mm}$. Intensities were recorded in continuous mode, at a scan rate of $1^{\circ} \mathrm{min}^{-1}$, and were integrated every $0.05^{\circ} 2 \theta$. Simulations of $h k$ bands were performed using software adapted to the study of defective lamellar structures (Plançon, 2002). This software is based on a matrix formalism (Drits \& Tchoubar, 1990), briefly overviewed in a previous publication (Grangeon, Claret, Linard \& Chiaberge, 2013), which was previously successfully used for the analysis of $\mathrm{C}-\mathrm{S}-\mathrm{H}$ structure and alteration mechanisms (Grangeon, Claret, Lerouge et al., 2013; Grangeon, Claret, Linard \& Chiaberge, 2013; Marty et al., 2015), as well as for the analysis of the structure of other cement phases (Roosz et al., 2015) and of nanocrystalline and defective manganese (e.g. Grangeon et al., 2008, 2010) and iron (Hadi et al., 2014) oxides. For all calculations, the structure model of an $11 \AA$ tobermorite (Merlino et al., 2001) was adapted, and the coherent scattering domain size in the $a b$ plane was set to $10 \mathrm{~nm}$. Owing to sample turbostratism, c cannot be defined (see e.g. Bish \& Post, 1990; Brindley \& Brown, 1980; Drits \& Tchoubar, 1990), and $\mathbf{c}^{*}$ (perpendicular to the $a b$ plane) will be used instead to refer to the direction perpendicular to the $a b$ plane (layer plane). Evolution of the intensity diffracted at $\sim 16.1^{\circ} 2 \theta \mathrm{Cu} K \alpha$ as a function of sample $\mathrm{Ca} / \mathrm{Si}$ ratio was monitored using the following formula: $I_{\text {rel }}=$ $\left[\left(I_{16.1^{\circ}{ }_{i} i} / I_{29.2^{\circ} \_i}\right)_{\mathrm{Ca} / \mathrm{Si}_{i} i}\right] /\left[\left(I_{16.1^{\circ} \_0.6} / I_{29.2^{\circ} \_0.6}\right)_{0.6}\right]$. In this calculation, $\left(I_{16.1^{\circ} i} i I_{29.2^{\circ} i}\right)_{\mathrm{Ca} / \mathrm{Si}_{i} i}$ stands for the intensity (background subtracted) of the maximum of the band at $\sim 16.1^{\circ} 2 \theta \mathrm{Cu} \mathrm{K \alpha}$ relative to the maximum of the band at $\sim 29.2^{\circ} 2 \theta \mathrm{Cu} \mathrm{K \alpha}$, for a given sample, and $\left(I_{16.1^{\circ} \_0.6} / I_{29.2^{\circ} \_0.6}\right)_{0.6}$ is the same calculation, but made for the sample of lowest $\mathrm{Ca} / \mathrm{Si}$ ratio (here, about 0.6). Consequently, the evolution of $I_{\text {rel }}$ as a function of $\mathrm{Ca} / \mathrm{Si}$ depicts the evolution of the intensity diffracted at $\sim 16.1^{\circ} 2 \theta$ $\mathrm{Cu} K \alpha$ relative to the maximum at $\sim 29.2^{\circ} 2 \theta \mathrm{Cu} K \alpha$ and to the sample of lowest $\mathrm{Ca} / \mathrm{Si}$.

The formalism used for the modelling of $00 l$ reflections (Plançon, 2002) allows for a change in the layer-to-layer distance without affecting the absolute coordinates (in ångströms) of atoms along the normal to the layer (coordinates along $\mathbf{a}$ and $\mathbf{b}$ are not needed for the calculation of $00 \mathrm{l}$ reflections). In other words, all distances and angles between layer atoms are kept identical to those of the original structure model [in this case, the model from Merlino et al. (2001)], while the interlayer spacing is varied. For a detailed description of the mathematical formalism used for the modelling of $00 l$ reflections, the reader is referred to previous publications (e.g. Drits et al., 1993; Plançon, 1981; Moore \& Reynolds, 1989; Sakharov \& Lanson, 2013). During the refinement of the 001 reflection, the sole free parameters were the layer-to-layer distance and the crystallite size perpendicular to the layer plane; that is, the mean number of layers stacked coherently (i.e. parallel to each other, albeit subject to random translation or rotations in the $a b$ plane). The occupancies of Si bridging tetrahedra and of interlayer Ca were, respectively, constrained using ${ }^{29} \mathrm{Si}$ NMR and EPMA. All instrumental parameters were constrained from the geometry of the experiment. The background was constrained to be the same for all samples and to be linearly decreasing with increasing ${ }^{\circ} 2 \theta$ values. Fit quality was evaluated with the usual $R_{\mathrm{wp}}, R_{\exp }$ and goodness of fit (GoF) factors (Howard \& Preston, 1989). Although the C-S$\mathrm{H}$ structure is suspected to be subject to interstratification, this phenomenon was not considered here, because only one of the $00 l$ reflections was observed, which does not provide enough information to constrain a possible interstratification phenomenon, and because this reflection was approximately symmetrical. Note that, in the samples of highest $\mathrm{Ca} / \mathrm{Si}$ ratio, the presence of nanocrystalline $\mathrm{Ca}(\mathrm{OH})_{2}$ sandwiched between two $\mathrm{C}-\mathrm{S}-\mathrm{H}$ layers (see below) could be understood as an interstratified structure, but can be described using a unique unit cell, because of the regular and systematic alternation, along $\mathbf{c}^{*}$, of the two types of 'layers'.

\section{Results}

\subsection{X-ray absorption}

XANES spectra of all samples and reference compounds are presented in Fig. 2. In all of the references, $\mathrm{Ca}$ is in the 
$\mathrm{Ca}^{2+}$ oxidation state, and the position of the main adsorption edge varies between $4047.9 \mathrm{eV}$ (dolomite) and $4050.6 \mathrm{eV}$ (portandite). In these references, the number of oxygen atoms to which $\mathrm{Ca}$ is bound is six (calcite, dolomite and portlandite), seven (tobermorite), eight (ettringite) or nine (gypsum). In agreement with literature data (Sowrey et al., 2004), the position of the main edge generally shifts towards higher energy when $\mathrm{Ca}$ coordination number increases, with the noticeable exception of portlandite, which has both the smallest $\mathrm{Ca}$ coordination number (six) and the highest absorption edge energy $(4050.6 \mathrm{eV})$. These observations are in agreement with literature data (Michel et al., 2008), in which the difference in the position of the main absorption edge of calcite and portlandite was found to be $+2.8 \mathrm{eV}(+2.6 \mathrm{eV}$ in the present study) and the difference between the calcite and aragonite edges $+1.3 \mathrm{eV}(+1.5 \mathrm{eV}$ in the present study). Finally, it should be noted that Ca was assumed to be sevenfold coordinated in tobermorite (i.e. only layer $\mathrm{Ca}$ was considered), although the coordination number may actually be slightly lower, owing to the possible presence of interlayer Ca whose coordination number may vary, for example as a function of sample hydration.

A first comparison of all C-S-H spectra (Fig. $2 b$ ) reveals no obvious difference between them, there being a generally similar $\mathrm{Ca}$ local environment over the whole range of $\mathrm{Ca} / \mathrm{Si}$ ratio investigated. Amongst all the references, the tobermorite spectrum is the closest to the $\mathrm{C}-\mathrm{S}-\mathrm{H}$ spectra, which shows that $\mathrm{Ca}$ has a similar local environment in tobermorite and all C-S$\mathrm{H}$ samples studied here. A closer examination, using derivative spectra (Fig. 2c), reveals that the main absorption edge of samples having a target $\mathrm{Ca} / \mathrm{Si}$ ratio of 0.83 (Table 1) is at $4049.6 \pm 0.1 \mathrm{eV}$, close to the tobermorite spectrum whose main edge is at $4049.4 \mathrm{eV}$. This indicates a close structural similarity between these $\mathrm{C}-\mathrm{S}-\mathrm{H}$ samples and tobermorite. Within uncertainties, the main edge is at the same position in these four samples and in the samples having a target $\mathrm{Ca} / \mathrm{Si}$ ratio of 0.6 and of 1.0. Consequently, the Ca local environment in these samples is, within the uncertainties, identical. Contrastingly, and relative to the samples having a target $\mathrm{Ca} / \mathrm{Si}$ ratio of 0.83 , the position of the main edge shifts towards higher energy when the $\mathrm{Ca} / \mathrm{Si}$ ratio increases, up to $4050.0 \mathrm{eV}$ for CSH $1.5-443 \mathrm{~K}$. This might reflect a change in Ca local environment when the structure slightly deviates from that of tobermorite but also the presence of Ca-rich impurities in samples having the highest $\mathrm{Ca} / \mathrm{Si}$ ratios $(\mathrm{CSH} 1.4-323 \mathrm{~K}$ and CSH 1.5-443 K). From analysis of literature data, this impurity could be $\mathrm{Ca}(\mathrm{OH})_{2}$ (e.g. Richardson, 2004, 2008, 2014; Richardson \& Groves, 1992a). This would be compatible with the present results, as the main edge of portlandite is at $4050.6 \mathrm{eV}$. Note that the presence of ettringite and (or) gypsum is not expected in the present samples, as the parent solution used for synthesis did not contain either $\mathrm{Al}$ or $\mathrm{S}$, and as these two elements could not be detected by EPMA.

\subsection{Fourier-transform infrared spectrometry}

The FTIR spectra of all of the C-S-H samples (Fig. 3) are very close to the tobermorite spectrum (Fig. 3; Yu et al., 1999) but differ from the jennite spectrum which has numerous absorption maxima, for example between 3465 and $3740 \mathrm{~cm}^{-1}$ (Carpenter et al., 1966; Yu et al., 1999).

In all of the spectra [which are here interpreted following Yu et al. (1999)], the series of bands in the $400-500 \mathrm{~cm}^{-1}$ range is related to $\mathrm{Si}-\mathrm{O}$ linkages, and the band at about $650 \mathrm{~cm}^{-1}$ is related to $\mathrm{Si}-\mathrm{O}-\mathrm{Si}$ bending vibrations, influenced by the $\mathrm{Si}-\mathrm{O}-\mathrm{Si}$ angle and the occupancy of neighbouring sites. The main band at $970 \mathrm{~cm}^{-1}$ is assigned to
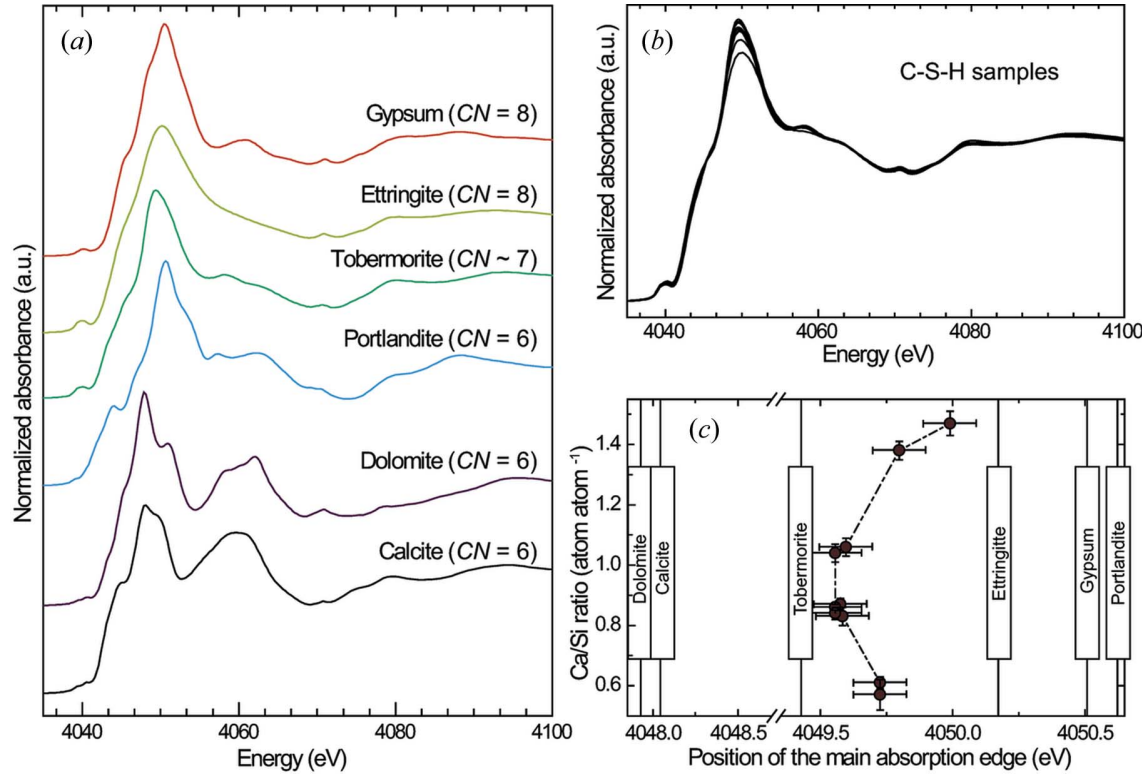
asymmetric stretching vibrations of $\mathrm{Si}-\mathrm{O}$ generated by $Q^{2}$ units (see $\$ 3.3$ for the definition of $Q^{2}$ ). The band at about $1630 \mathrm{~cm}^{-1}$ is ascribed to $\mathrm{H}-\mathrm{O}-\mathrm{H}$ bending vibrations of molecular $\mathrm{H}_{2} \mathrm{O}$, and the broad band centred around $3430 \mathrm{~cm}^{-1}$ to $\mathrm{O}-\mathrm{H}$ stretching vibrations. Such assignments were confirmed using $a b$ initio molecular dynamics (Churakov, 2009a,b). The maxima appearing in the range 1350$1550 \mathrm{~cm}^{-1}$ are attributed to $\left(\mathrm{CO}_{3}\right)^{2-}$. The presence of a peak at $875 \mathrm{~cm}^{-1}$ suggests this is calcium carbonate. The evolution of the intensity of the bands at 875 and 1350 $1550 \mathrm{~cm}^{-1}$ as a function of $\mathrm{Ca} / \mathrm{Si}$ ratio is best described with a two-step process (inset in Fig. 3): the absorbance is low and constant when the $\mathrm{Ca} / \mathrm{Si}$ ratio is lower than or equal to $0.87 \pm 0.02$ and then increases with the $\mathrm{Ca} / \mathrm{Si}$ ratio at higher ratios. As samples were kept in an $\mathrm{N}_{2}$-saturated glove-box, and were exposed to air only a few tens of minutes prior to measurement,
Reference $(a)$ and C-S-H (b) XANES spectra. $C N$ stands for 'calcium coordination number'. See text for details. (c) The relation between $\mathrm{Ca} / \mathrm{Si}$ ratio and position of the main edge (dots) in each of the studied C-S-H samples as well as the position of the main edge in each of the references (vertical lines with associated caption). 
the sensitivity to fast carbonation processes increases with the $\mathrm{Ca} / \mathrm{Si}$ ratio. In agreement with the XANES results, this is best explained by assuming that samples having a $\mathrm{Ca} / \mathrm{Si}$ ratio higher than $0.87 \pm 0.02$ contain a growing proportion of a Carich impurity that would be sensitive to carbonation, such as $\mathrm{Ca}(\mathrm{OH})_{2}$. Similar preferential carbonation of samples of high $\mathrm{Ca} / \mathrm{Si}$ ratio was observed in a series of eight dried samples having $\mathrm{Ca} / \mathrm{Si}$ ratios ranging between 0.41 and 1.70 (Yu et al., 1999).

\section{3. ${ }^{29} \mathrm{Si}$ nuclear magnetic resonance}

C-S-H ${ }^{29}$ Si MAS NMR spectra are shown in Fig. 4. The three main resonances at $-79 /-80,-84.5 /-85.5$ and $-92 /$ $-94 \mathrm{ppm}$ are respectively assigned, following previous literature studies (Brunet et al., 2004; Cong \& Kirkpatrick, 1996b; Cong \& Kirkpatrick, 1996a; Maeshima et al., 2003; Pardal et al., 2012; Richardson et al., 2010), to $Q^{1}, Q^{2}$ and $Q^{3}$ sites. These three $\mathrm{Si}$ sites are typical for calcium silicate hydrates (Fig. 1). In a $Q^{1}$ site, an Si atom is only connected to another $\mathrm{Si}$ atom, and this site is generally assigned to $\mathrm{Si}$ atoms forming paired tetrahedra at the surface of the $\mathrm{C}-\mathrm{S}-\mathrm{H} \mathrm{Ca}$ layer (Fig. 1). In a $Q^{2}$ site, an $\mathrm{Si}$ atom is connected to two other

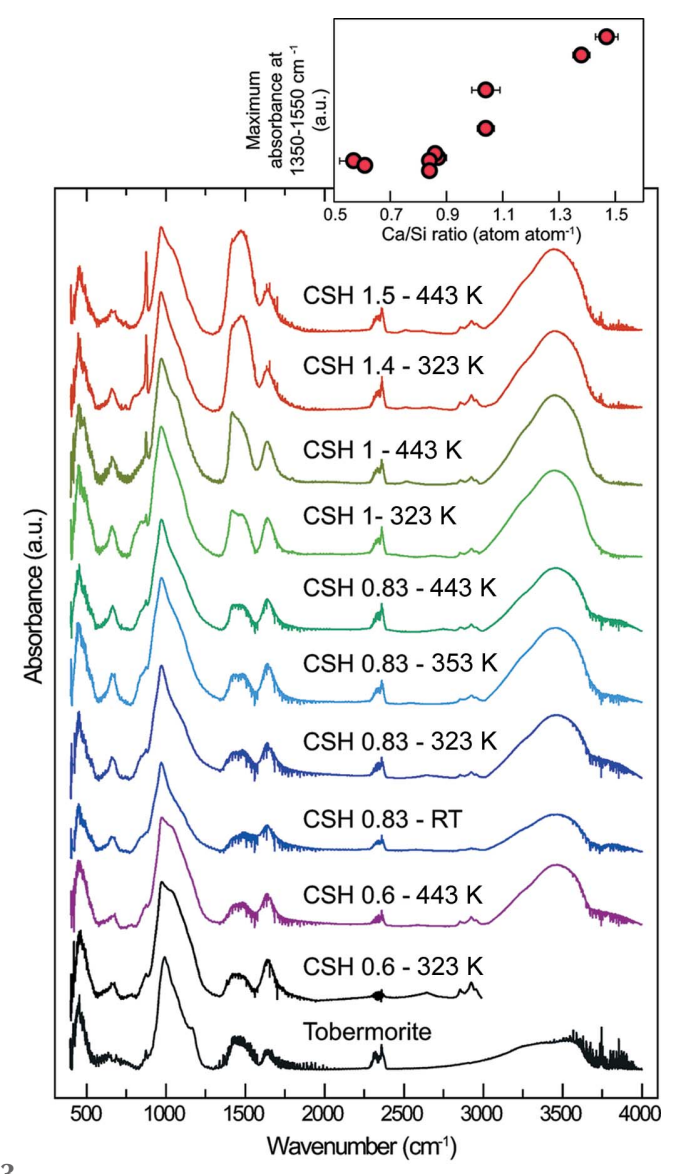

Figure 3

Main panel: FTIR spectra of all studied C-S-H samples. From top to bottom, spectra are sorted by decreasing target $\mathrm{Ca} / \mathrm{Si}$ ratio and by decreasing synthesis temperature. The inset at the top right shows the evolution of the maximum of the absorbance at $1350-1550 \mathrm{~cm}^{-1}$ as a function of sample $\mathrm{Ca} / \mathrm{Si}$ ratio.
Table 2

Relative abundance of the different ${ }^{29} \mathrm{Si}$ sites retrieved from analysis of ${ }^{29} \mathrm{Si}$ MAS NMR data, mean Si chain length, and maximum $\mathrm{Ca} / \mathrm{Si}$ ratio that could be reached if the charge resulting from all vacant Si tetrahedra was compensated for by interlayer $\mathrm{Ca}(\mathrm{Ca} / \mathrm{Si} \max )$.

n.d. stands for 'not detected'.

\begin{tabular}{|c|c|c|c|c|c|}
\hline \multirow[b]{2}{*}{ Sample } & \multicolumn{3}{|c|}{$\begin{array}{l}\text { Relative abundance of } \\
\text { the different }{ }^{29} \mathrm{Si} \text { sites }(\%)\end{array}$} & \multirow{2}{*}{$\begin{array}{l}\text { Mean chain } \\
\text { length (number } \\
\text { of Si tetrahedra) }\end{array}$} & \multirow[b]{2}{*}{$\begin{array}{l}\mathrm{Ca} / \mathrm{Si} \\
\max \dagger\end{array}$} \\
\hline & $Q^{1}$ & $Q^{2}$ & $Q^{3}$ & & \\
\hline CSH $0.6-323 \mathrm{~K}$ & $4.2 \pm 1.5$ & $55.6 \pm 3.0$ & $40.2 \pm 1.5$ & 48 & 1.02 \\
\hline CSH $0.6-443 \mathrm{~K}$ & $4.0 \pm 1.8$ & $53.6 \pm 3.6$ & $42.4 \pm 1.8$ & 50 & 1.02 \\
\hline CSH $0.83-\mathrm{RT}$ & $16.4 \pm 2.1$ & $78.3 \pm 4.2$ & $5.3 \pm 2.1$ & 12 & 1.08 \\
\hline CSH $0.83-323 \mathrm{~K}$ & $12.1 \pm 1.0$ & $87.9 \pm 2.0$ & n.d. & 17 & 1.06 \\
\hline CSH $0.83-353 \mathrm{~K}$ & $9.4 \pm 1.0$ & $80.2 \pm 2.0$ & $10.5 \pm 1.0$ & 21 & 1.05 \\
\hline CSH $0.83-443 \mathrm{~K}$ & $11.0 \pm 1.8$ & $77.8 \pm 3.6$ & $11.1 \pm 1.8$ & 18 & 1.06 \\
\hline CSH $1.0-323 \mathrm{~K}$ & $40.8 \pm 5.3$ & $59.2 \pm 10.6$ & n.d. & 5 & 1.20 \\
\hline CSH $1.0-443 \mathrm{~K}$ & $26.0 \pm 4.8$ & $74.0 \pm 9.6$ & n.d. & 8 & 1.13 \\
\hline CSH $1.4-323 \mathrm{~K}$ & $68.1 \pm 3.8$ & $32.0 \pm 7.6$ & n.d. & 3 & 1.34 \\
\hline CSH $1.5-443$ K & $39.5 \pm 6.2$ & $60.4 \pm 12.4$ & n.d. & 5 & 1.20 \\
\hline
\end{tabular}

$\dagger$ Maximum $\mathrm{Ca} / \mathrm{Si}$ ratio that could be reached assuming that the charge originating from a vacant Si site is compensated for by interlayer Ca (Richardson, 2014).

$\mathrm{Si}$ atoms, and this site corresponds either to an $\mathrm{Si}$ atom bridging two of the aforementioned $\mathrm{Si}$ atoms or to an $\mathrm{Si}$ atom from paired tetrahedra connected to this bridging $\mathrm{Si}$ tetrahedron. As previously observed (e.g. Lequeux et al., 1999; Noma et al., 1998), the chemical shift associated with the $Q^{2}$ environment varies with the $\mathrm{Ca} / \mathrm{Si}$ ratio (Fig. $4 c$ ), from $-85.60 \mathrm{ppm}(\mathrm{CSH}$ $0.6-323 \mathrm{~K}$ ) to $-84.35 \mathrm{ppm}(\mathrm{CSH} 1.5-443 \mathrm{~K})$. This is probably linked to an evolution of $\mathrm{Si}$ local environment, as discussed below. Finally, the nature of the $Q^{3}$ site is subject to discussion, in particular because the corresponding band is broad (Fig. 4). It may be assigned to a bridging $\mathrm{Si}$ atom connected to another one from the adjacent layer through its apical oxygen (Fig. 1; Trapote-Barreira et al., 2014), or to silanols resulting from incomplete dissolution of the amorphous silica used for synthesis (e.g. Brinker et al., 1988; Leonardelli et al., 1992). The presence of silanols, which are remnants from the synthesis reactants, is likely in CSH $0.6-323 \mathrm{~K}$ and CSH $0.6-443 \mathrm{~K}$, as their $\mathrm{Ca} / \mathrm{Si}$ ratio is lower than the minimum value of $2 / 3$ that can be obtained assuming a tobermorite-like structure. Taking into account this chemical constraint and assuming that these samples contain a mix of silanols and of a C-S-H having a Ca/ Si ratio of 2/3, CSH $0.6-323 \mathrm{~K}$ and CSH $0.6-443 \mathrm{~K}$, respectively, contain $7-22$ and $0-12 \%$ of silanols.

The proportion of each Si environment does not depend on synthesis temperature, whereas the $\mathrm{Ca} / \mathrm{Si}$ ratio has a major influence (Table 2 and Fig. 5). The proportion of $Q^{1}$ environment increases with the $\mathrm{Ca} / \mathrm{Si}$ ratio, from $4.2 \pm 1.5 \%$ and $4.0 \pm 1.8 \%$ for, respectively, $\mathrm{CSH} 0.6-323 \mathrm{~K}(\mathrm{Ca} / \mathrm{Si}$ ratio of $0.57 \pm 0.05)$ and $\mathrm{CSH} 0.6-443 \mathrm{~K}(\mathrm{Ca} / \mathrm{Si}$ ratio of $0.61 \pm 0.02)$ up to $68.1 \pm 3.8 \%$ for $\mathrm{CSH} 1.4-323 \mathrm{~K}(\mathrm{Ca} / \mathrm{Si}$ ratio of $1.38 \pm 0.03)$. The evolution of the $Q^{2}$ environment is more complex, being equal to $55.6 \pm 3.0 \%$ and $53.6 \pm 3.6 \%$ for, respectively, $\mathrm{CSH}$ $0.6-323 \mathrm{~K}$ and $\mathrm{CSH} 0.6-443 \mathrm{~K}$, increasing up to $87.9 \pm 2 \%$ for $\mathrm{CSH} 0.83-323 \mathrm{~K}(\mathrm{Ca} / \mathrm{Si}$ ratio of $0.87 \pm 0.02)$ and then decreasing at higher $\mathrm{Ca} / \mathrm{Si}$ ratios, down to $32.0 \pm 7.6 \%$ for 

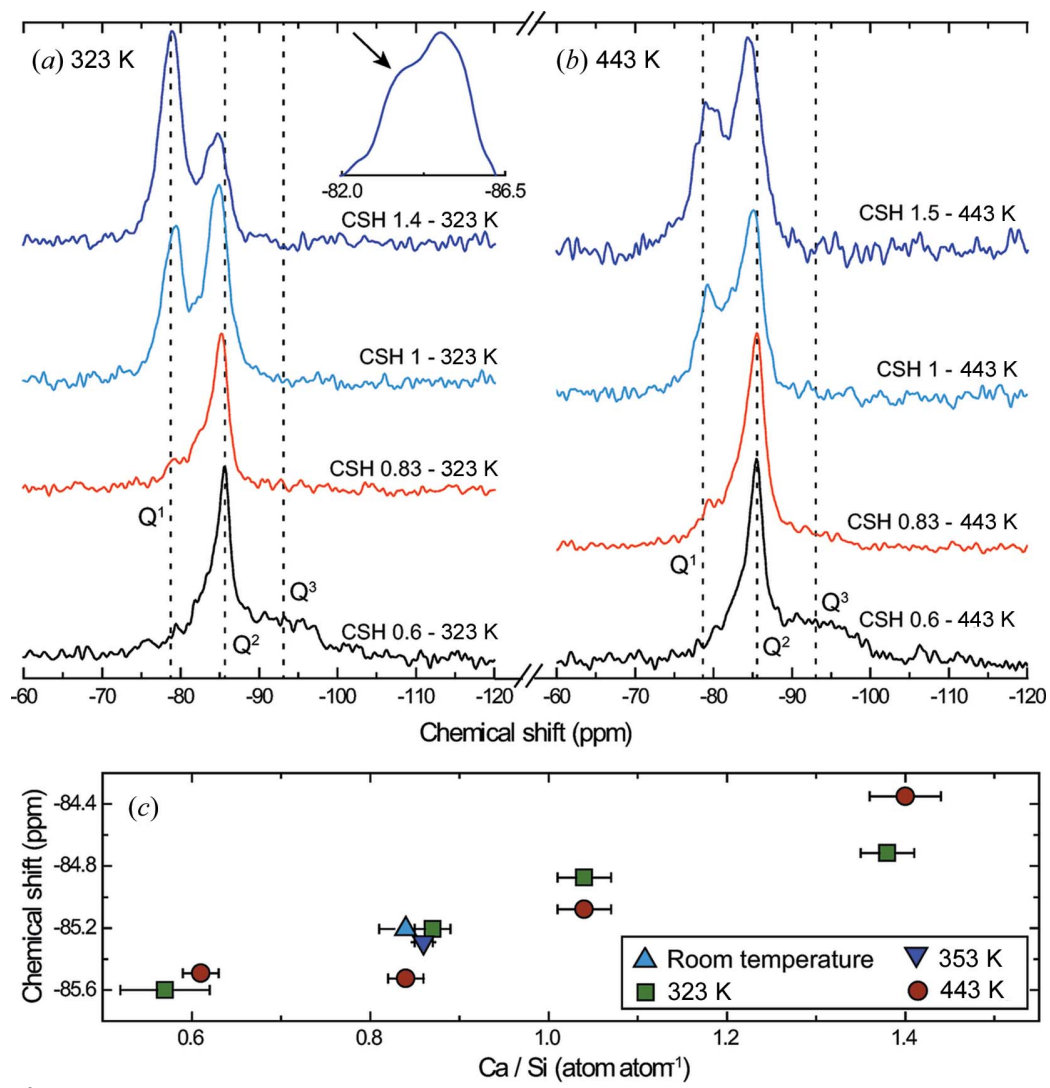

Figure 4

${ }^{29}$ Si MAS NMR spectra acquired on C-S-H samples synthesized at $323 \mathrm{~K}(a)$ and $443 \mathrm{~K}$ (b), and evolution of the $Q^{2}$ chemical shift as a function of sample Ca/Si ratio (c). In (a) and $(b)$, spectra are sorted, from top to bottom, by decreasing $\mathrm{Ca} / \mathrm{Si}$ ratio and dashed vertical lines show the approximate position of, from left to right, Si $Q^{1}, Q^{2}$ and $Q^{3}$ environments. The inset in (a) points, with the example of CSH $1.4-323 \mathrm{~K}$, to the appearance of a shoulder on the resonance of the $Q^{2}$ environment when the $\mathrm{Ca} / \mathrm{Si}$ ratio increases. In (c), samples synthesized at room temperature, $353 \mathrm{~K}, 323 \mathrm{~K}$ and $443 \mathrm{~K}$ are, respectively, shown as up and down triangles, squares and dots.

CSH $1.4-323 \mathrm{~K}(\mathrm{Ca} / \mathrm{Si}$ ratio of $1.38 \pm 0.03)$. Finally, the proportion of $Q^{3}$ environment decreases with increasing $\mathrm{Ca} / \mathrm{Si}$ ratio, from $40.2 \pm 1.5 \%$ (CSH $0.6-323 \mathrm{~K})$ down to 0 when the $\mathrm{Ca} / \mathrm{Si}$ ratio is $0.87 \pm 0.02$ or higher. From chemical consid-

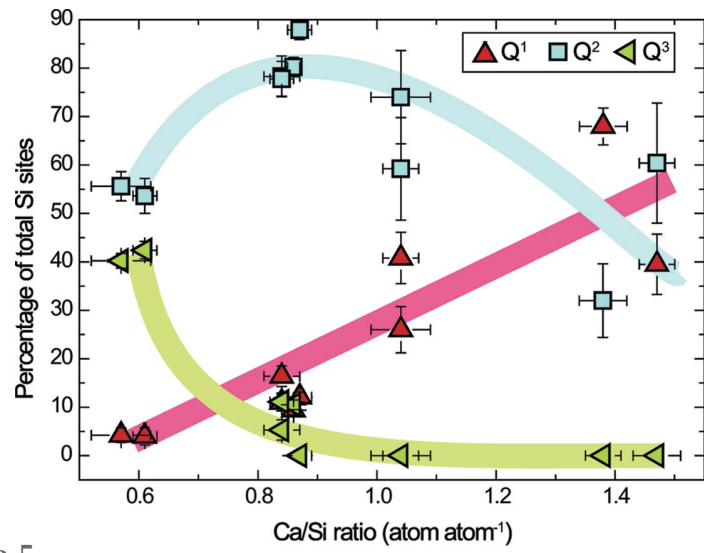

Figure 5

Evolution of the proportion of $\mathrm{Si} Q^{1}$ (triangles pointing to the top), $Q^{2}$ (squares) and $Q^{3}$ (triangles pointing to the left) environments as a function of sample $\mathrm{Ca} / \mathrm{Si}$ ratio, as retrieved from analysis of ${ }^{29} \mathrm{Si} \mathrm{MAS}$ NMR data. Solid lines are intended to be guides for the eye. erations (see above), even if silanols could be present in CSH $0.6-323 \mathrm{~K}$ and $\mathrm{CSH} 0.6-443 \mathrm{~K}$, they do not account for more than $12 \%$ of the total $\mathrm{Si}$ in CSH $0.6-443 \mathrm{~K}$ and $22 \%$ in CSH $0.6-323 \mathrm{~K}$. Thus, these samples contain $\mathrm{Si}$ in a $Q^{3}$ configuration. For the three other samples in which a $Q^{3}$ environment is detected (CSH 0.83-RT, CSH $0.83-353 \mathrm{~K}$ and CSH $0.83-443 \mathrm{~K}$ ), the ratio of $Q^{3}$ to $Q^{1}$ is lower than that expected for a doublechain tobermorite $\left[Q^{3}=1 / 3-Q^{1} / 2\right.$ following Richardson (2014)], probably because of the nanocrystallinity of the presently studied samples. Indeed, with 3-4 layers stacked coherently on average (see below), $25-33 \%$ of $\mathrm{Si}$ wollastonitelike chains are exposed at the particle surface, in which all Si bridging tetrahedra are connected at most to two Si atoms ( $Q^{2}$ environment) instead of three $\left(Q^{3}\right.$ environment) in the interlayer space.

The main length of Si chain (the mean number of Si tetrahedra connected in the wollastonite-like chains) decreases with the $\mathrm{Ca} / \mathrm{Si}$ ratio (Table 2), being equal to 48 for the lowest $\mathrm{Ca} / \mathrm{Si}$ ratio $(0.57 \pm$ $0.05)$ and having a minimum value of $3(\mathrm{Ca} / \mathrm{Si}=$ $1.38 \pm 0.03)$.

\subsection{Powder X-ray diffraction}

The XRD patterns of all of the C-S-H samples have a high degree of similarity (Fig. 6). They are all attributable to a tobermorite-like structure affected by nanocrystallinity and turbostratism (Grangeon, Claret, Lerouge et al., 2013; Grangeon, Claret, Linard \& Chiaberge, 2013), the former inducing broad diffraction maxima and the latter cancelling $h k l$ reflections with $h \neq 0$ and $k \neq 0$ (Drits \& Tchoubar, 1990). All maxima are $00 l$ reflections and $h k$ bands.

Amongst the diffraction maxima, the 001 reflection (at $\sim 7.4^{\circ} 2 \theta \mathrm{Cu} K \alpha$ ) has the most pronounced variations, both in position and in intensity (Fig. 6). It is absent in three samples (CSH 0.6-323 K, CSH 0.6-443 K and CSH 1.5-443 K) and very weak in a fourth sample (CSH 1.0-443 K). In these samples, crystallites are thus overwhelmingly built of isolated layers, which means that the crystals are essentially made of isolated layers or of layers not stacked parallel to each other. When observable, the 001 reflection shifts towards low $d$ spacing (high diffraction angles) with increasing $\mathrm{Ca} / \mathrm{Si}$ ratio (inset in Fig. 6), from $12.9 \pm 0.4 \AA$ for samples having a target $\mathrm{Ca} / \mathrm{Si}$ ratio of 0.83 , down to $11.9 \pm 0.1 \AA$ for the sample having a $\mathrm{Ca} / \mathrm{Si}$ ratio of $1.38 \pm 0.03$. Such variation is commonly observed (Garbev, Beuchle et al., 2008; Matsuyama \& Young, 2000; Renaudin et al., 2009; Richardson, 2014; Walker et al., 2007) and cannot be related, in the present study, to a change in the mean number of layers stacked parallel to each other with varying $\mathrm{Ca} / \mathrm{Si}$ ratio, as the full width at half-maximum of this reflection is similar in all samples. The evolution of the layer-to-layer distance was further assessed by modelling the 
001 reflection when it was present (Fig. 7 and Table 3). Consistently with qualitative observation, the layer-to-layer distance decreases from 12.25 to $11.50 \AA$ for samples having a $\mathrm{Ca} / \mathrm{Si}$ ratio varying between $0.84 \pm 0.02$ and $0.87 \pm 0.02$, down to $11 \AA$ for CSH $1.4-323 \mathrm{~K}$ which has a $\mathrm{Ca} / \mathrm{Si}$ ratio of $1.38 \pm$ 0.03 . Such values are about $1 \AA$ smaller than those deduced from the qualitative examination of the position of the 001 reflection, as a result of sample nanocrystallinity (Drits \& Tchoubar, 1990; Reynolds, 1968, 1986). This demonstrates that any study of the layer-to-layer distance in nanocrystalline layered phases cannot rely solely on the qualitative study of this reflection. The nanocrystallinity of the presently studied samples is confirmed by the results of these calculations, as the crystallite size perpendicular to the layer plane is $4-5 \mathrm{~nm}$ for all modelled patterns (Table 3).

Another variation in intensity is observed on the band at $\sim 16.1^{\circ} 2 \theta \mathrm{Cu} \mathrm{K \alpha}$ (Fig. 6). When normalized to the intensity of the band at $\sim 29.2^{\circ} 2 \theta \mathrm{Cu} \mathrm{K \alpha}$, it steadily decreases in intensity with increasing $\mathrm{Ca} / \mathrm{Si}$ ratio, in agreement with previous observations (Fig. 8). From analysis of literature data and the present study, the main parameters that are susceptible to evolving as a function of the $\mathrm{Ca} / \mathrm{Si}$ ratio are the occupancy of $\mathrm{Si}$ bridging tetrahedra in the wollastonite-like chains (e.g. Myers et al., 2013; Richardson, 2014) and the abundance of interlayer water (Kim et al., 2013; Marty et al., 2015). The

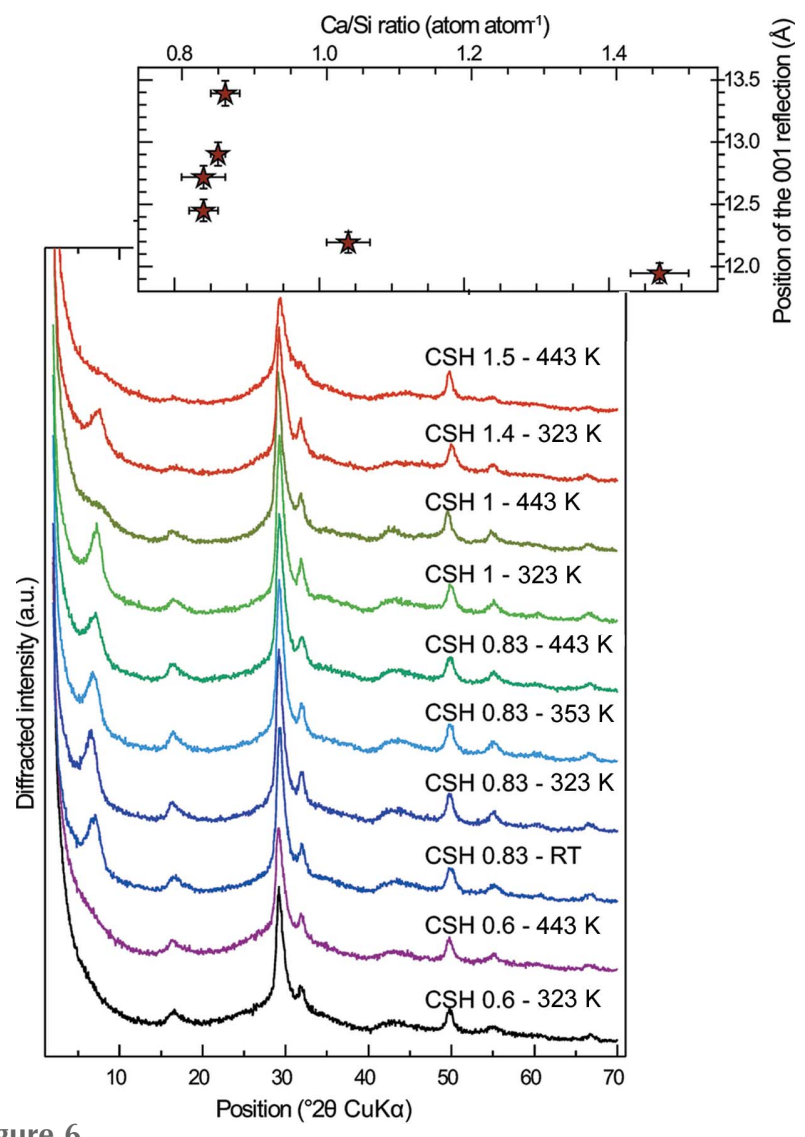

Figure 6

Main panel: XRD pattern of all studied samples, sorted as in Fig. 3. The inset at the top right shows the evolution of the position of the 001 reflection (when observable) as a function of sample $\mathrm{Ca} / \mathrm{Si}$ ratio.
Table 3

Crystal data derived from analysis of the 001 reflection.

$R_{\mathrm{wp}}, R_{\exp }$ and $\mathrm{GoF}$ were calculated over the $2-15^{\circ} 2 \theta \mathrm{Cu} K \alpha$ angular range.

\begin{tabular}{|c|c|c|c|c|c|}
\hline Sample & $\begin{array}{l}\text { Layer-to-layer } \\
\text { distance }(\AA)\end{array}$ & $\begin{array}{l}\text { Mean number of } \\
\text { layers stacked } \\
\text { coherently }\end{array}$ & $R_{\mathrm{wp}}(\%)$ & $\mathrm{R}_{\exp }(\%)$ & GoF \\
\hline CSH $0.83-\mathrm{RT}$ & 11.75 & 3.7 & 6.08 & 3.25 & 3.51 \\
\hline CSH $0.83-323 \mathrm{~K}$ & 12.25 & 3.3 & 6.02 & 3.21 & 3.53 \\
\hline CSH $0.83-353 \mathrm{~K}$ & 11.75 & 3.4 & 6.59 & 3.21 & 4.21 \\
\hline CSH $0.83-443 \mathrm{~K}$ & 11.50 & 3.5 & 7.35 & 3.26 & 5.10 \\
\hline CSH $1.0-323 \mathrm{~K}$ & 11.50 & 4.2 & 8.75 & 3.24 & 7.28 \\
\hline CSH $1.4-323 \mathrm{~K}$ & 11.00 & 4.1 & 8.76 & 3.30 & 7.06 \\
\hline
\end{tabular}

impact of these two parameters on XRD patterns was tested here (Fig. 8). It can be observed that the intensity of the band at $\sim 16.1^{\circ} 2 \theta \mathrm{Cu} \mathrm{K \alpha}$ mainly depends on the occupancy of Si atoms in the bridging site, with the diffracted intensity decreasing with decreasing $\mathrm{Si}$ occupancy (Fig. 8b). The abundance of interlayer water has a minor effect (Fig. 8c). Consequently, XRD and ${ }^{29} \mathrm{Si}$ NMR consistently show that as the $\mathrm{Ca} / \mathrm{Si}$ ratio increases the wollastonite-like chains depolymerize through omission of bridging $\mathrm{Si}$ tetrahedra. This is in
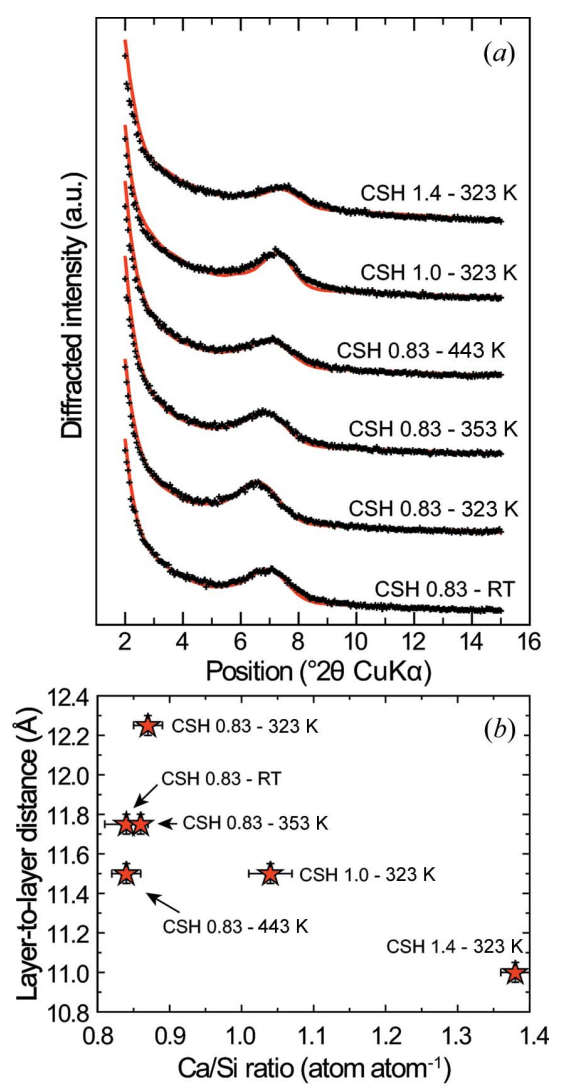

Figure 7

(a) Data (black crosses) and best simulation (red solid line) of the 001 reflection from, from top to bottom, CSH $1.4-323 \mathrm{~K}$, CSH $1.0-323 \mathrm{~K}$, CSH $0.83-443 \mathrm{~K}$, CSH $0.83-353 \mathrm{~K}$, CSH $0.83-323 \mathrm{~K}$ and CSH $0.83-\mathrm{RT}$ $\mathrm{XRD}$ patterns. The deduced evolution of the layer-to-layer distance as a function of sample $\mathrm{Ca} / \mathrm{Si}$ ratio is shown in $(b)$. All simulation results are given in Table 3 . 
agreement with the study of Matsuyama \& Young (2000), who also observed, using ${ }^{29} \mathrm{Si} \mathrm{NMR,} \mathrm{that} \mathrm{Si}$ chains depolymerize when the sample $\mathrm{Ca} / \mathrm{Si}$ ratio increases, and who provided XRD patterns in which it can be observed that the intensity of the band at $\sim 16.1^{\circ} 2 \theta \mathrm{CuK \alpha}$ relative to that of the band at $\sim 29.2^{\circ} 2 \theta \mathrm{Cu} K \alpha$ weakens when the $\mathrm{Ca} / \mathrm{Si}$ ratio increases (Fig. $8 a$ ).
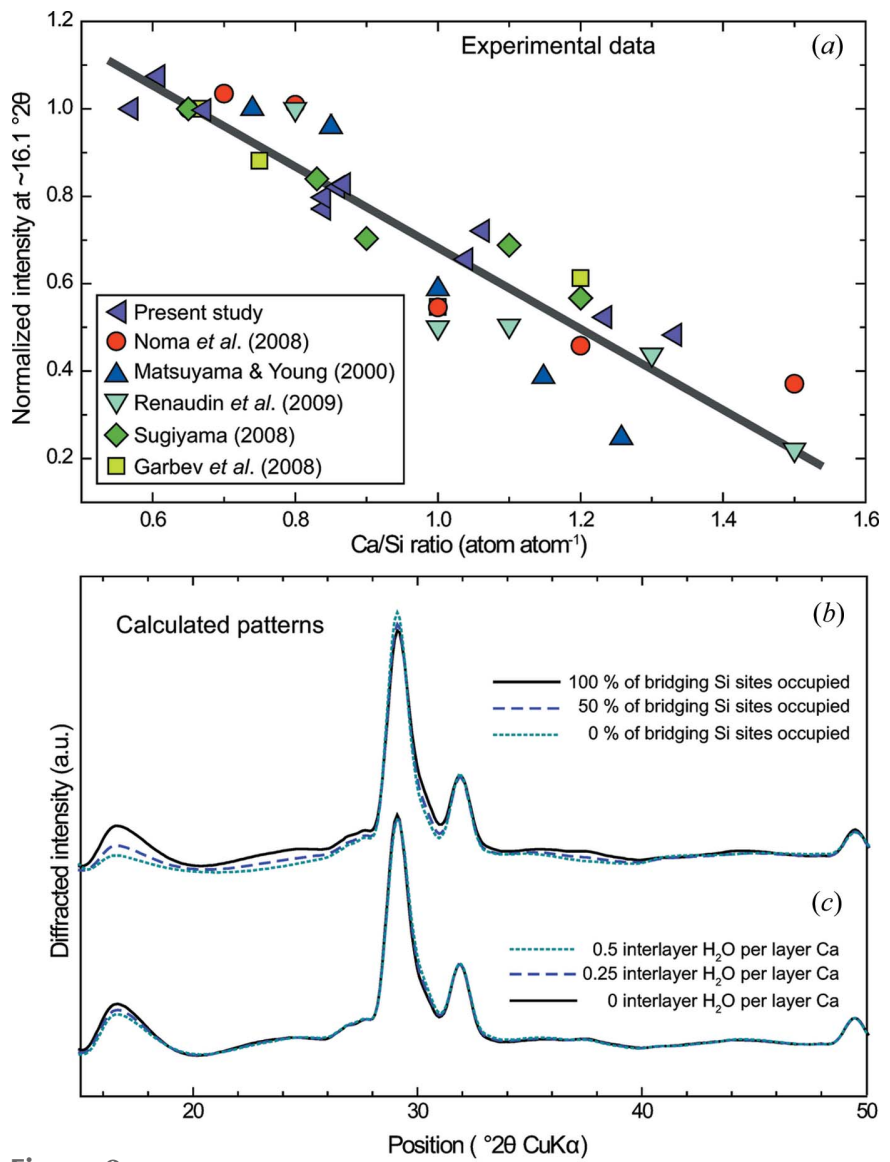

Figure 8

(a) Evolution of the normalized intensity of the diffraction maximum at $\sim 16.1^{\circ} 2 \theta \mathrm{Cu} \mathrm{K \alpha}\left(I_{\text {rel }}\right.$; see text for details) as a function of sample $\mathrm{Ca} / \mathrm{Si}$ ratio. Data presented in Fig. 4 and additional data acquired for the present study (XRD patterns not shown) are shown with solid purple triangles pointing to the left. These data are compared with literature data, shown with solid red circles (Noma et al., 1998), solid blue triangles pointing to the top (Matsuyama \& Young, 2000), solid cyan triangles pointing to the bottom (Renaudin et al., 2009), solid green diamonds (Sugiyama, 2008) and solid light-green squares (Garbev, Beuchle et al., 2008; Garbev, Bornefeld et al., 2008). Only studies performed on dried samples were considered, as this band may be influenced by the content of interlayer water. Data scattering is probably a result of the normalization procedure (related both to the data digitalization method and to the fact that some studies did not present data for samples having a $\mathrm{Ca} / \mathrm{Si}$ of $\sim 0.6$ ) and a possible variable content of, for example, interlayer $\mathrm{Ca}$. The solid grey line is the best linear fit to the data $(y=-0.913 x+$ 1.597; $\left.r^{2}=0.9\right) .(b),(c)$ Calculations that show the dependence of XRD patterns on the occupancy of Si bridging tetrahedra in the wollastonitelike chains $(b)$ (solid black, dashed purple and dotted blue lines are calculations where the occupancy of Si bridging tetrahedra is, respectively, 1, 0.5 and 0 ) and on the abundance of interlayer water (c) (solid black, dashed purple and dotted blue lines are calculations where the number of interlayer water molecules is, respectively, $0.5,0.25$ and 0 per layer calcium).

\section{Discussion}

\subsection{Evolution of $\mathrm{C}-\mathrm{S}-\mathrm{H}$ structure as a function of its $\mathrm{Ca} / \mathrm{Si}$} ratio

The present study provides evidence for $\mathrm{C}-\mathrm{S}-\mathrm{H}$ being nanocrystalline and turbostratic tobermorite over the whole range of $\mathrm{Ca} / \mathrm{Si}$ ratio investigated. A mechanism for the structure evolution as a function of $\mathrm{Ca} / \mathrm{Si}$ ratio is now proposed in the following sections.

4.1.1. Structure of the samples of low $\mathrm{Ca} / \mathrm{Si}$ ratio $(\mathrm{CSH}$ $0.6-323 \mathrm{~K}$ and $\mathrm{CSH} 0.6-443 \mathrm{~K}$ ). In CSH 0.6-323 K and CSH $0.6-443 \mathrm{~K}(\mathrm{Ca} / \mathrm{Si}$ ratios of $0.57 \pm 0.05$ and $0.61 \pm 0.02)$, the $Q^{3}$ environment accounts for $40-42 \%$ of the total $\mathrm{Si}$ and, even if part of these sites are remnants from the reactants used for the synthesis (see above), layer-to-layer connectivity through bridging Si tetrahedra exists. In apparent contradiction, XRD shows that crystallites are built of isolated layers. However, because XRD probes crystallites (i.e. coherent scattering domains) and not crystals, the apparent discrepancy between XRD and ${ }^{29}$ Si NMR can straightforwardly be reconciled by assuming that stacking disorder occurs not only via turbostratism but also via loss of parallelism between adjacent layers. This may be understood as resulting from a slight corrugation of the layers [as previously schematized (Brunauer \& Greenberg, 1960; Feldman \& Sereda, 1968; Jennings, 2008) or observed (Marty et al., 2015; Richardson et al., 2010)]. As successive layers are connected through Si bridging tetrahedra, random translations (and rotations) in the $a b$ plane certainly are of limited amplitude and, by analogy with tobermorite, the layer-to-layer distance in CSH 0.6-323 K and CSH $0.6-443 \mathrm{~K}$ is certainly close to $11.3 \AA$ (Merlino et al., 1999, 2001). In addition, some of the bridging Si tetrahedra in a $Q^{3}$ configuration may be missing, thus allowing for a local change in the layer-to-layer distance, which would be compatible with layer corrugation. Taking all this information into account, the structure may be close to a defective clinotobermorite (Richardson, 2014), being affected by turbostratism and layer corrugation. It should be noted that other studies have observed a 001 reflection at about $14 \AA$ in samples of comparable $\mathrm{Ca} / \mathrm{Si}$ ratio (Grangeon, Claret, Linard \& Chiaberge, 2013; Matsuyama \& Young, 2000; Richardson, 2014), which could in certain cases indicate that layer-to-layer connectivity through Si bridging tetrahedra is absent (Garbev, Beuchle et al., 2008; Garbev, Bornefeld et al., 2008). This means that different $\mathrm{C}-\mathrm{S}-\mathrm{H}$ preparation and (or) conditioning or ageing methods can lead to slightly different $\mathrm{C}-\mathrm{S}-\mathrm{H}$ structures, and the results obtained here for the $\mathrm{C}-\mathrm{S}-\mathrm{H}$ samples having $\mathrm{Ca} / \mathrm{Si}$ ratios of $\sim 0.6$ are probably not applicable to all $\mathrm{C}-\mathrm{S}-\mathrm{H}$ specimens.

The presence of the $\mathrm{Si} Q^{1}$ environment in these samples (Table 2) may be understood as the presence of isolated paired $\mathrm{Si}$ tetrahedra, which would require a locally strong Si chain depolymerization. However, a crystal that is $10 \mathrm{~nm}$ in width in the $a b$ plane (as reported for samples synthesized using the same method; Grangeon, Claret, Lerouge et al., 2013) and has defect-free Si chains contains $\sim 33 \% Q^{3}, \sim 63 \% Q^{2}$ and $\sim 5 \%$ $Q^{1}$, these latter resulting from border truncation effects. This is 
in good agreement with experimental values (Table 2), especially when the contribution of silanols originating from the reactants used for sample synthesis is taken into account, and indicates that the $Q^{1}$ sites detected in CSH $0.6-323 \mathrm{~K}$ and CSH $0.6-443 \mathrm{~K}$ result mainly from sample nanocrystallinity. The minute size of $\mathrm{C}-\mathrm{S}-\mathrm{H}$ crystals can be further assessed using ${ }^{29} \mathrm{Si} \mathrm{NMR}$, as the mean Si chain length (Table 2) is calculated to be at most (because of the excess of $Q^{3}$ ) $48-50 \mathrm{Si}$ atoms $(\sim 12 \mathrm{~nm})$.

4.1.2. Structural evolution with increasing $\mathrm{Ca} / \mathrm{Si}$ ratio. A scheme of the proposed $\mathrm{C}-\mathrm{S}-\mathrm{H}$ structural evolution as a function of $\mathrm{Ca} / \mathrm{Si}$ ratio, detailed here below, is proposed in Fig. 9.

As the $\mathrm{Ca} / \mathrm{Si}$ ratio increases from $0.57 \pm 0.05$ to $0.86 \pm 0.01$, the proportion of $\mathrm{Si} Q^{3}$ environment decreases down to $5.3 \pm$ $2.1 \%$, while the proportions of $Q^{1}$ and $Q^{2}$ environments increase and, respectively, peak at $16.4 \pm 2.1 \%$ and $80.2 \pm 2 \%$. Thus, when the $\mathrm{Ca} / \mathrm{Si}$ ratio increases, depolymerization of the wollastonite-like Si chain occurs, certainly via omission of bridging Si tetrahedra as supported by XRD (Fig. 8), and layer-to-layer connectivity through $\mathrm{Si}$ bridging tetrahedra weakens, allowing for an increase in the layer-to-layer distance (Figs. 5 and 7; Table 3) and possibly for a higher magnitude of random stacking faults. In addition, when an $\mathrm{Si}$ atom in $Q^{3}$ conformation is removed, the geometrical conformation of the corresponding remaining bridging $Q^{2} \mathrm{Si}$ tetrahedron evolves, as the number of $\mathrm{Si}$ atoms coordinating the apical oxygen is reduced from two to one. Both a higher magnitude of the random stacking faults and a change in the coordination sphere of Si bridging tetrahedra would explain the chemical shift of the Si $Q^{2}$ environment (Fig. 4), which is thought to occur in the case of stacking disorder (Cong \& Kirkpatrick,
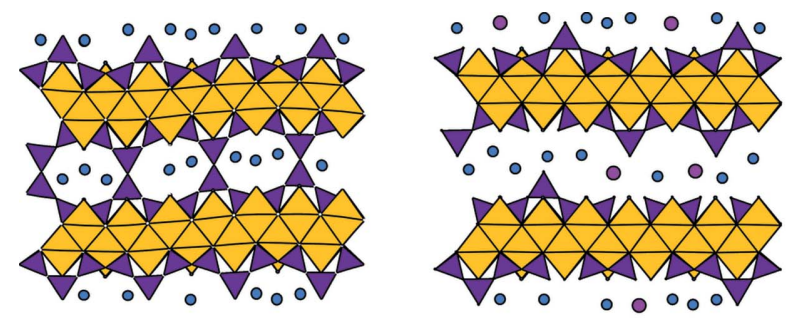

Increase in $\mathrm{Ca} / \mathrm{Si}$ ratio

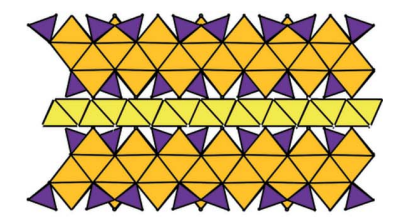

$\mathrm{Ca} / \mathrm{Si}=3 / 2$

\section{$\diamond$ Layer Ca $\triangle$ Layer Si - Interlayer $\mathrm{H}_{2} \mathrm{O}$ ○ Interlayer $\mathrm{Ca}$ \\ $\triangle \mathrm{Ca}(\mathrm{OH})_{2}$}

Figure 9

Proposed evolution of $\mathrm{C}-\mathrm{S}-\mathrm{H}$ structure as a function of its $\mathrm{Ca} / \mathrm{Si}$ ratio. At low $\mathrm{Ca} / \mathrm{Si}$ ratio, the structure is a nanocrystalline turbostratic tobermorite having corrugated layers. When the $\mathrm{Ca} / \mathrm{Si}$ ratio increases, Si bridging tetrahedra are progressively removed. A first step of structural evolution consists in an increase of the layer-to-layer distance, because layer-to-layer connectivity weakens. In a second step, layer-to-layer distance decreases, because interlayer $\mathrm{Ca}$ is progressively incorporated and holds the layers together. In a final step, Ca coordination spheres connect to form interlayer $\mathrm{Ca}(\mathrm{OH})_{2}$ resembling portlandite. The structure of samples having a $\mathrm{Ca} / \mathrm{Si}$ of $\sim 1.5$ shares a number of similarities with the Richardson (2014) model, except that that model is three-dimensionally ordered, whereas the present one assumes turbostratism, but these two models can straightforwardly be reconciled (see text). The final step of structural evolution could not be observed here, as all samples contained some Si bridging tetrahedra. Note that the structure of the samples of lowest $\mathrm{Ca} / \mathrm{Si}$ ratio may vary depending on the synthesis procedure, as some other studies have observed the absence of connectivity between adjacent layers (see text for details).
$1996 b$ ) and probably results from a change in the $\mathrm{Si}-\mathrm{O}-\mathrm{Si}$ gle between connected Si tetrahedra (Magi et al., 1984). the observed magnitude of the Si chain depolymer$\mathrm{Ca} / \mathrm{Si}$ ra not exceed $16.4 \pm 2.1 \%$, the $\mathrm{Ca} / \mathrm{Si}$ ratio should be at most $\sim 0.7$ if only layer $\mathrm{Ca}$ is considered. Thus, samples having a $\mathrm{Ca} / \mathrm{Si}$ ratio ranging between $0.84 \pm 0.03$ and $0.86 \pm 0.0 .1$ certainly Intain interlayer $\mathrm{Ca}$. layer connectivity through bridging $\mathrm{Si}$ tetrahedra is lost. This is is $0.5-8 \mathrm{~A}$. layer-to-layer distance of $12.3 \mathrm{~A}$, which ent is detect (i.e. in which layer-to-layer connecof $Q^{2}$ Si bridging tetrahedra remains). The proportion compared to $53.6 \pm 3.6 \%$ in CSH $0.6-443 \mathrm{~K}$, whereas the proportion of $\mathrm{Si} Q^{1}$ environment is $12.1 \pm 1.0 \%$ as compared were in $Q^{3}$ confiar above, this sample contains interlayer $\mathrm{Ca}$ which contributes to Ang every layer parallel to each other.

CSH $0.83-323 \mathrm{~K}$, none of the samples havi these samples, the proportion of $\mathrm{Si} Q^{2}$ environment decreases with the $\mathrm{Ca} / \mathrm{Si}$ ratio, down to $32.0 \pm 7.6 \%$ when $\mathrm{Ca} / \mathrm{Si}$ ratio the remains of the wollastonite-like $\mathrm{Si}$ chain are mainly built of paired $\mathrm{Si}$ tetrahedra (in a $Q^{1}$ configuration; Fig. 1), and the mean Si chain length is 3-5 (Table 2). Again, in order to explain the observed $\mathrm{Ca} / \mathrm{Si}$ ratio of these samples, the presence of interlayer $\mathrm{Ca}$ (or of a discrete Ca-rich impurity) has to be considered. Indeed, a structure with all Si bridging tetrahedra omitted (i.e. all being in a $Q^{1}$ configuration) and no interlayer $\mathrm{Ca}$ would have a $\mathrm{Ca} / \mathrm{Si}$ ratio of 1 . Introducing interlayer $\mathrm{Ca}$ up to the maximum possible interlayer occupancy while avoiding sharing of hydration spheres (similarly to tobermorite $\mathrm{MDO} 2$ from the Urals or plombierite; Bonaccorsi et al., 2005; Merlino et al., 2001) and assuming that $\mathrm{Ca}$ can only occupy a single interlayer plane owing to the observed layer-tolayer distance (Fig. 7) leads to a $\mathrm{Ca} / \mathrm{Si}$ ratio of 1.25 . To reach a $\mathrm{Ca} / \mathrm{Si}$ ratio of 1.5 , it must be assumed that interlayer 
Ca atoms connect through their hydration sphere and form 'layers' that have many structural similarities with nanocrystalline portlandite (Girão et al., 2010; Grangeon, Claret, Linard \& Chiaberge, 2013; Richardson, 2014). These 'layers' can be understood as interstratified with a $\mathrm{C}-\mathrm{S}-\mathrm{H}$ layer structure having bridging $\mathrm{Si}$ tetrahedra omitted (Fig. 9; Garbev, Beuchle et al., 2008; Garbev, Bornefeld et al., 2008; Girão et al., 2010; Grangeon, Claret, Linard \& Chiaberge, 2013; Nonat, 2004; Richardson, 2014). This is compatible with the observed layer-to-layer distance reduction when the $\mathrm{Ca} / \mathrm{Si}$ ratio increases from $0.87 \pm 0.02$ to $1.38 \pm 0.03$. Taking portlandite as a model structure, the typical height of a $\mathrm{Ca}(\mathrm{OH})_{2}$ octahedron is $2.3 \AA$ (Busing \& Levy, 1957), whereas two bridging Si tetrahedra connected through their apical oxygen have a height of $4.4 \AA$ (Merlino et al., 1999, 2001). In this assumption, the layer-to-layer distance can theoretically reduce down to $\sim 9.4 \AA$ if all $\mathrm{Si}$ bridging tetrahedra are omitted and if interlayer $\mathrm{Ca}(\mathrm{OH})_{2}$ forms a 'layer' (Richardson, 2014). This was not observed in the presently studied samples, even at high $\mathrm{Ca} / \mathrm{Si}$ ratios, because all samples still contain a few Si bridging tetrahedra which probably prevent the structure from collapsing.

The presence of $\mathrm{Ca}(\mathrm{OH})_{2}$ is in agreement with chargebalance calculations, as the observed $\mathrm{Ca} / \mathrm{Si}$ ratios of $\mathrm{CSH} 1.4$ $323 \mathrm{~K}$ and $\mathrm{CSH} 1.5-443 \mathrm{~K}$ are higher than the values that could be reached assuming that the charge arising from a vacant $\mathrm{Si}$ tetrahedron is balanced by interlayer $\mathrm{Ca}(\mathrm{Ca} / \mathrm{Si} \max$ in Table 2), meaning that $\mathrm{Ca}$ is in excess in the structure. It is also in agreement with TEM observations of intimate mixing of $\mathrm{C}-\mathrm{S}-\mathrm{H}$ and $\mathrm{Ca}(\mathrm{OH})_{2}$ (Richardson et al., 2010), with studies which used thermogravimetry to show that samples having a $\mathrm{Ca} / \mathrm{Si}$ higher than $\sim 1.25$ contain a Ca-rich component which melts at the temperature expected for $\mathrm{Ca}(\mathrm{OH})_{2}(\mathrm{Kim}$ et al., 2013; Marty et al., 2015), and with nano-indentation models (Chen et al., 2010; Vandamme \& Ulm, 2013). The presence of interlayer Ca subject to carbonation, such as a portlandite-like phase, would explain the observed preferential carbonation in samples of high $\mathrm{Ca} / \mathrm{Si}$ ratio (present study; Yu et al., 1999) and the XANES observation that samples of high $\mathrm{Ca} / \mathrm{Si}$ ratio have a component that could be close in structure to portlandite (Fig. 2).

Previous studies have shown that the increase in sensitivity to carbonation with increasing $\mathrm{Ca} / \mathrm{Si}$ ratio is much lower for wet samples, in which the infrared absorption band at $\sim 1350$ $1550 \mathrm{~cm}^{-1}$ is significant only for samples having a Ca/Si ratio higher than $\sim 1.4$ (Walker et al., 2007). This may indicate that the interlayer $\mathrm{Ca}(\mathrm{OH})_{2}$ would not exist in wet samples, perhaps because it dissolves preferentially when the sample is introduced into an aqueous medium [or, conversely, it could be interpreted as $\mathrm{Ca}(\mathrm{OH})_{2}$ structure formation in the interlayer space during water removal resulting from sample freeze-drying]. This hypothesis of a change in Ca distribution upon wetting (or drying) would explain the contrasting views from structure and chemical studies, where the former (performed on dried samples) suggest the presence of $\mathrm{Ca}(\mathrm{OH})_{2}$ (e.g. Chen et al., 2010; Girão et al., 2010; Richardson, 2014) while the latter (performed on aqueous suspensions) suggest that $\mathrm{Ca}$ accumulates at the particle surface through physical adsorption, thus explaining the observed charge inversion as a function of $\mathrm{pH}$ conditions (e.g. Labbez et al., 2006, 2007). Such a hypothesis is consistent with the fact that, when $\mathrm{C}-\mathrm{S}-\mathrm{H}$ is immersed in a solution containing sodium, this cation is in the diffuse ion swarm, whereas it forms an outersphere complex, possibly in the $\mathrm{C}-\mathrm{S}-\mathrm{H}$ interlayer, when the sample is dried (Viallis et al., 1999).

\subsection{Use of X-ray diffraction to study $\mathrm{C}-\mathrm{S}-\mathrm{H}$ structure}

C-S-H XRD patterns are sometimes considered to be typical of an 'X-ray amorphous' phase (e.g. Kulik \& Kersten, 2001; Nonat, 2004), perhaps because they contain only a few broad and weak diffraction maxima and because, in contrast to other nanocrystalline turbostratic structures (Grangeon et al., 2014), modification of the XRD patterns upon variation of the chemical composition (here, $\mathrm{Ca} / \mathrm{Si}$ ratio) is limited (Fig. 6). However, the present article, in combination with previous work, allows us to propose indicators for the qualitative and quantitative study of $\mathrm{C}-\mathrm{S}-\mathrm{H}$ structure.

First, it is proposed for the first time that the occupancy of bridging $\mathrm{Si}$ sites in the wollastonite-like chains can be estimated from the study of the maximum at $\sim 16.1^{\circ} 2 \theta \mathrm{Cu} \mathrm{K \alpha}$ (Fig. 8). Second, the 001 reflection whose position generally varies between 6.5 and $8.0^{\circ} 2 \theta \mathrm{Cu} \mathrm{K \alpha}$ can be exploited in two different manners: First, its breadth is indicative of the crystallite size along $\mathbf{c}^{*}$ (mean number of layers stacked parallel to each other); the larger the breadth, the lower the crystallite size, although other factors such as microstrains or interstratification play a role (Grangeon, Claret, Linard \& Chiaberge, 2013). Second, its position might be used as a proxy for the layer-to-layer distance (if the breadth of the reflection remains constant), but this has to be used with care. If the layer-to-layer distance is homogeneous in the crystallites forming the sample and if the crystallite size along $\mathbf{c}^{*}$ is about constant, then the observed position of the 001 reflection is a function of the layer-to-layer distance. However, in the case of $\mathrm{C}-\mathrm{S}-\mathrm{H}$, interstratification and (or) variation of crystallite size as a function of $\mathrm{Ca} / \mathrm{Si}$ ratio may exist (Grangeon, Claret, Linard \& Chiaberge, 2013). Consequently, quantitative analysis of the $00 l$ reflections is recommended. Finally, the crystallite size in the $a b$ plane (i.e. lateral extension of $\mathrm{C}-\mathrm{S}-\mathrm{H}$ crystallites) can be probed through the study of the breadth of the two maxima at 29.3 and $30^{\circ} 2 \theta \mathrm{Cu} \mathrm{K \alpha}$, which both broaden when the crystallite size in the $a b$ plane decreases. The evolution of $a$ can be estimated from the study of the position of the maximum at $\sim 30^{\circ} 2 \theta \mathrm{Cu} \mathrm{K \alpha}$, which shifts towards higher $d$ spacing (low-angle side) when $a$ increases. The evolution of $b$ can be estimated using the same methodology and the study of the maximum at $\sim 29.3^{\circ} 2 \theta \mathrm{Cu} K \alpha$.

Overall, the study of $\mathrm{C}-\mathrm{S}-\mathrm{H}$ diffraction patterns in the reciprocal lattice, as done here and previously on other (nanocrystalline) turbostratic phases such as clays (Gates et al., 2002), carbon black (Warren, 1941), Mn oxides (Grangeon et al., 2012) and $\mathrm{Fe}$ oxides (Hadi et al., 2014), appears to be a traditional yet promising way to study $\mathrm{C}-\mathrm{S}-\mathrm{H}$ structure. 
Additional information may be obtained from the study of XRD patterns in real space, using high-energy X-ray scattering and analysis in the pair distribution function formalism (Skinner et al., 2010; Soyer-Uzun et al., 2012), which allows one to attenuate the effect of the intrinsic structural disorder (e.g. nanocrystallinity and turbostratism) reigning in $\mathrm{C}-\mathrm{S}-\mathrm{H}$, as also demonstrated for nanocrystalline Mn oxides (Manceau et al., 2013; Grangeon et al., 2015).

\section{Conclusion}

The present study aimed to contribute to a better understanding of $\mathrm{C}-\mathrm{S}-\mathrm{H}$ structure, when its $\mathrm{Ca} / \mathrm{Si}$ ratio varies from $\sim 0.6$ to $\sim 1.5$. At low $\mathrm{Ca} / \mathrm{Si}$ ratio, $\mathrm{C}-\mathrm{S}-\mathrm{H}$ is a turbostratic nanocrystalline tobermorite having, to the precision of the methods used, defect-free $\mathrm{Si}$ chains. When the $\mathrm{Ca} / \mathrm{Si}$ ratio increases, the main structure evolution is the progressive depolymerization of $\mathrm{Si}$ chains through progressive omission of $\mathrm{Si}$ bridging tetrahedra and the progressive incorporation of interlayer $\mathrm{Ca}$ to compensate for the resulting layer charge. At the highest $\mathrm{Ca} / \mathrm{Si}$ ratios, interlayer $\mathrm{Ca}$ may polymerize, possibly in the interlayer space, to form a structure that has many structural similarities with $\mathrm{Ca}(\mathrm{OH})_{2}$. Formation of a $\mathrm{Ca}(\mathrm{OH})_{2}$ phase is supported by the fact that $\mathrm{Ca}$ is in excess in the structure.

It has been demonstrated that modelling of powder XRD patterns may be used to quantitatively determine structure parameters such as crystallite size or layer-to-layer distance. In addition, it is proposed that the occupancy of Si bridging tetrahedra can also be estimated from analysis of XRD patterns through the study of the modulation at $\sim 16.1^{\circ} 2 \theta$ $\mathrm{Cu} K \alpha$. In particular, a new method, based solely on the qualitative examination of the patterns, has been established and proved to be consistent with available literature data. Further studies, using independent methods of analysis, are required to consolidate these results.

To conclude, it must be remembered that this study was performed on freeze-dried samples. However, $\mathrm{C}-\mathrm{S}-\mathrm{H}$ is a nanocrystalline lamellar structure. As such, it has external (surface) and internal (interlayer) adsorption sites, to which calcium can attach. By analogy with clay minerals, water certainly has an impact on $\mathrm{C}-\mathrm{S}-\mathrm{H}$ structure, in particular through a change in the calcium hydration sphere. This is supported by the fact that water has an influence on Portland cement pastes (Feldman \& Sereda, 1968). However, the potential influence of hydration/dehydration cycles on C-S-H structure remains to be investigated.

\section{Acknowledgements}

The authors are grateful to Dr A. Lahfid for fruitful discussions, to Dr V. Montouillout for NMR data acquisition, to Dr C. Lerouge for acquisition of EPMA and FTIR data, and to C. Numako for XANES data acquisition. SG acknowledges funding by the French national research agency (Agence Nationale de la Recherche - ANR; NACRE project; grant
ANR-14-CE01-0006). This article benefited from comments and suggestions made by three anonymous reviewers.

\section{References}

Abdolhosseini Qomi, M. J., Krakowiak, K. J., Bauchy, M., Stewart, K. L., Shahsavari, R., Jagannathan, D., Brommer, D. B., Baronnet, A., Buehler, M. J., Yip, S., Ulm, F. J., Van Vliet, K. J. \& Pellenq, R. J. M. (2014). Nat. Commun. 5, 4960.

Andersen, M. D., Jakobsen, H. J. \& Skibsted, J. (2003). Inorg. Chem. 42, 2280-2287.

Bach, T. T. H., Chabas, E., Pochard, I., Cau Dit Coumes, C., Haas, J., Frizon, F. \& Nonat, A. (2013). Cem. Concr. Res. 51, 14-21.

Bish, D. L. \& Post, J. E. (1990). Editors. Modern Powder Diffraction. Washington, DC: The Mineralogical Society of America.

Blanc, P., Bourbon, X., Lassin, A. \& Gaucher, E. C. (2010). Cem. Concr. Res. 40, 851-866.

Bonaccorsi, E., Merlino, S. \& Kampf, A. R. (2005). J. Am. Ceram. Soc. 88, 505-512.

Brindley, G. W. \& Brown, G. (1980). Editors. Crystal Structures of Clay Minerals and Their X-ray Identification, ch. 2. London: Mineralogical Society.

Brinker, C. J., Kirkpatrick, R. J., Tallant, D. R., Bunker, B. C. \& Montez, B. (1988). J. Non-Cryst. Solids, 99, 418-428.

Brunauer, S. \& Greenberg, S. A. (1960). Chemistry of Cement: Proceedings of the Fourth International Symposium. Washington, DC: US National Bureau of Standards.

Brunet, F., Bertani, P., Charpentier, T., Nonat, A. \& Virlet, J. (2004). J. Phys. Chem. B, 108, 15494-15502.

Busing, W. R. \& Levy, H. A. (1957). J. Chem. Phys. 26, 563-568.

Carpenter, A. B., Chalmers, R. A., Gard, J. A., Speakman, K. \& Taylor, H. F. W. (1966). Am. Mineral. 51, 56-74.

Chatterji, S. (1997). J. Am. Ceram. Soc. 80, 2959-2960.

Chen, J. J., Sorelli, L., Vandamme, M., Ulm, F. J. \& Chanvillard, G. (2010). J. Am. Ceram. Soc. 93, 1484-1493.

Churakov, S. V. (2009a). Am. Mineral. 94, 156-165.

Churakov, S. V. (2009b). Eur. J. Mineral. 21, 261-271.

Churakov, S. V., Labbez, C., Pegado, L. \& Sulpizi, M. (2014). J. Phys. Chem. C, 118, 11752-11762.

Cong, X. \& Kirkpatrick, R. J. (1996a). Adv. Cem. Based Mater. 3, $133-$ 143.

Cong, X. \& Kirkpatrick, R. J. (1996b). Adv. Cem. Based Mater. 3, 144-156.

Drits, V. A., Sakharov, B. A., Salyn, A. L. \& Manceau, A. (1993). Clay Miner. 28, 185-207.

Drits, V. A. \& Tchoubar, C. (1990). X-ray Diffraction by Disordered Lamellar Structures: Theory and Applications to Microdivided Silicates and Carbons. Berlin: Springer-Verlag.

Etzold, M. A., McDonald, P. J. \& Routh, A. F. (2014). Cem. Concr. Res. 63, 137-142.

Faucon, P., Charpentier, T., Nonat, A. \& Petit, J. C. (1998). J. Am. Chem. Soc. 120, 12075-12082.

Faucon, P., Delagrave, A., Richet, C., Marchand, J. M. \& Zanni, H. (1999). J. Phys. Chem. B, 103, 7796-7802.

Feldman, R. F. \& Sereda, P. J. (1968). Mater. Constr. (Paris), 1, 509520.

Garbev, K., Beuchle, G., Bornefeld, M., Black, L. \& Stemmermann, P. (2008). J. Am. Ceram. Soc. 91, 3005-3014.

Garbev, K., Bornefeld, M., Beuchle, G. \& Stemmermann, P. (2008). J. Am. Ceram. Soc. 91, 3015-3023.

Gates, W. P., Slade, P. G., Manceau, A. \& Lanson, B. (2002). Clays Clay Miner. 50, 223-239.

Girão, A. V., Richardson, I. G., Taylor, R. \& Brydson, R. M. D. (2010). Cem. Concr. Res. 40, 1350-1359.

Grangeon, S., Claret, F., Lerouge, C., Warmont, F., Sato, T., Anraku, S., Numako, C., Linard, Y. \& Lanson, B. (2013). Cem. Concr. Res. 52, 31-37. 
Grangeon, S., Claret, F., Linard, Y. \& Chiaberge, C. (2013). Acta Cryst. B69, 465-473.

Grangeon, S., Fernandez-Martinez, A., Warmont, F., Gloter, A., Marty, N., Poulain, A. \& Lanson, B. (2015). Geochem. Trans. 16, 12. Grangeon, S., Lanson, B. \& Lanson, M. (2014). Acta Cryst. B70, 828838.

Grangeon, S., Lanson, B., Lanson, M. \& Manceau, A. (2008). Mineral. Mag. 72, 1279-1291.

Grangeon, S., Lanson, B., Miyata, N., Tani, Y. \& Manceau, A. (2010). Am. Mineral. 95, 1608-1616.

Grangeon, S., Manceau, A., Guilhermet, J., Gaillot, A.-C., Lanson, M. \& Lanson, B. (2012). Geochim. Cosmochim. Acta, 85, 302-313.

Groves, G. W., Sueur, P. J. \& Sinclair, W. (1986). J. Am. Ceram. Soc. 69, 353-356.

Hadi, J., Grangeon, S., Warmont, F., Seron, A. \& Greneche, J.-M. (2014). J. Colloid Interface Sci. 434, 130-140.

Heller, L. \& Taylor, H. F. W. (1956). Crystallographic Data for the Calcium Silicates. London: Her Majesty's Stationery Office.

Howard, S. A. \& Preston, K. D. (1989). Rev. Mineral. Geochem. 20, 217-275.

Isaure, M.-P., Laboudigue, A., Manceau, A., Sarret, G., Tiffreau, C., Trocellier, P., Lamble, G., Hazemann, J.-L. \& Chateigner, D. (2002). Geochim. Cosmochim. Acta, 66, 1549-1567.

Jennings, H. M. (2008). Cem. Concr. Res. 38, 275-289.

Kim, J. J., Foley, E. M. \& Reda Taha, M. M. (2013). Cem. Concr. Compos. 36, 65-70.

Kirkpatrick, R. J., Yarger, J. L., McMillan, P. F., Ping, Y. \& Cong, X. (1997). Adv. Cem. Based Mater. 5, 93-99.

Korpa, A. \& Trettin, R. (2006). Cem. Concr. Res. 36, 634-649.

Kulik, D. A. \& Kersten, M. (2001). J. Am. Ceram. Soc. 84, 3017-3026.

Labbez, C., Jönsson, B., Pochard, I., Nonat, A. \& Cabane, B. (2006). J. Phys. Chem. B, 110, 9219-9230.

Labbez, C., Nonat, A., Pochard, I. \& Jönsson, B. (2007). J. Colloid Interface Sci. 309, 303-307.

Leonardelli, S., Facchini, L., Fretigny, C., Tougne, P. \& Legrand, A. P. (1992). J. Am. Chem. Soc. 114, 6412-6418.

Lequeux, N., Morau, A., Philippot, S. \& Boch, P. (1999). J. Am. Ceram. Soc. 82, 1299-1306.

Maeshima, T., Noma, H., Sakiyama, M. \& Mitsuda, T. (2003). Cem. Concr. Res. 33, 1515-1523.

Magi, M., Lippmaa, E., Samoson, A., Engelhardt, G. \& Grimmer, A. R. (1984). J. Phys. Chem. 88, 1518-1522.

Manceau, A., Marcus, M. A., Grangeon, S., Lanson, M., Lanson, B., Gaillot, A.-C., Skanthakumar, S. \& Soderholm, L. (2013). J. Appl. Cryst. 46, 193-209.

Manzano, H., Dolado, J. S., Guerrero, A. \& Ayuela, A. (2007). Phys. Status Solidi (A), 204, 1775-1780.

Marcus, M. A., MacDowell, A. A., Celestre, R., Manceau, A., Miller, T., Padmore, H. A. \& Sublett, R. E. (2004). J. Synchrotron Rad. 11, 239-247.

Marty, N. C. M., Grangeon, S., Warmont, F. \& Lerouge, C. (2015). Mineral. Mag. 79, 437-458.

Massiot, D., Fayon, F., Capron, M., King, I., Le Calvé, S., Alonso, B., Durand, J.-O., Bujoli, B., Gan, Z. \& Hoatson, G. (2002). Magn. Reson. Chem. 40, 70-76.

Matsuyama, H. \& Young, J. F. (2000). Adv. Cem. Res. 12, 29-33.

Merlino, S., Bonaccorsi, E. \& Armbruster, T. (1999). Am. Mineral. 84, 1613-1621.

Merlino, S., Bonaccorsi, E. \& Armbruster, T. (2001). Eur. J. Miner. 13, 577-590.

Michel, F. M., MacDonald, J., Feng, J., Phillips, B. L., Ehm, L., Tarabrella, C., Parise, J. B. \& Reeder, R. J. (2008). Chem. Mater. 20, 4720-4728.

Moore, D. M. \& Reynolds, R. C. (1989). X-ray Diffraction and the Identification and Analysis of Clay Minerals. Oxford University Press.

Myers, R. J., Bernal, S. A. \& Provis, J. L. (2014). Cem. Concr. Res. 66, 27-47.
Myers, R. J., Bernal, S. A., San Nicolas, R. \& Provis, J. L. (2013). Langmuir, 29, 5294-5306.

Myers, R. J., L'Hôpital, E., Provis, J. L. \& Lothenbach, B. (2015). Cem. Concr. Res. 68, 83-93.

Noma, H., Adachi, Y., Yamada, H., Nishino, T., Matsuda, Y. \& Yokoyama, T. (1998). Nuclear Magnetic Resonance Spectroscopy of Cement-Based Materials, edited by P. Colombet, H. Zanni, A.-R. Grimmer \& P. Sozzani, pp. 159-168. Berlin, Heidelberg: Springer.

Nomura, M. \& Koyama, A. (2001). Nucl. Instrum. Methods Phys. Res. Sect. A, 467-468, 733-736.

Nonat, A. (2004). Cem. Concr. Res. 34, 1521-1528.

Pardal, X., Brunet, F., Charpentier, T., Pochard, I. \& Nonat, A. (2012). Inorg. Chem. 51, 1827-1836.

Pegado, L., Labbez, C. \& Churakov, S. V. (2014). J. Mater. Chem. A, 2, 3477-3483.

Pellenq, R. J.-M., Kushima, A., Shahsavari, R., Van Vliet, K. J., Buehler, M. J., Yip, S. \& Ulm, F.-J. (2009). Proc. Natl Acad. Sci. USA, 106, 16102-16107.

Plançon, A. (1981). J. Appl. Cryst. 14, 300-304.

Plançon, A. (2002). J. Appl. Cryst. 35, 377.

Renaudin, G., Russias, J., Leroux, F., Frizon, F. \& Cau-dit-Coumes, C. (2009). J. Solid State Chem. 182, 3312-3319.

Reynolds, R. C. (1968). Acta Cryst. A24, 319-320.

Reynolds, R. C. (1986). Clays Clay Miner. 34, 359-367.

Richardson, I. G. (1999). Cem. Concr. Res. 29, 1131-1147.

Richardson, I. G. (2004). Cem. Concr. Res. 34, 1733-1777.

Richardson, I. G. (2008). Cem. Concr. Res. 38, 137-158.

Richardson, I. G. (2014). Acta Cryst. B70, 903-923.

Richardson, I. G., Brough, A. R., Groves, G. W. \& Dobson, C. M. (1994). Cem. Concr. Res. 24, 813-829.

Richardson, I. G. \& Groves, G. W. (1992a). Cem. Concr. Res. 22, 1001-1010.

Richardson, I. G. \& Groves, G. W. (1992b). J. Mater. Sci. 27, 6204 6212.

Richardson, I. G. \& Groves, G. W. (1993). J. Mater. Sci. 28, 265277.

Richardson, I. G., Skibsted, J., Black, L. \& Kirkpatrick, R. J. (2010). Adv. Cem. Res. 22, 233-248.

Roosz, C., Grangeon, S., Blanc, P., Montouillout, V., Lothenbach, B., Henocq, P., Giffaut, E., Vieillard, P. \& Gaboreau, S. (2015). Cem. Concr. Res. 73, 228-237.

Sakharov, B. A. \& Lanson, B. (2013). Handbook of Clay Science, edited by B. Faïza \& L. Gerhard, ch. 2.3, pp. 51-136. Amsterdam: Elsevier.

Skinner, L. B., Chae, S. R., Benmore, C. J., Wenk, H. R. \& Monteiro, P. J. M. (2010). Phys. Rev. Lett. 104, 195502.

Sowrey, F. E., Skipper, L. J., Pickup, D. M., Drake, K. O., Lin, Z., Smith, M. E. \& Newport, R. J. (2004). Phys. Chem. Chem. Phys. 6, 188-192.

Soyer-Uzun, S., Chae, S. R., Benmore, C. J., Wenk, H.-R. \& Monteiro, P. J. M. (2012). J. Am. Ceram. Soc. 95, 793-798.

Sugiyama, D. (2008). Cem. Concr. Res. 38, 1270-1275.

Taylor, H. F. W. (1986). J. Am. Ceram. Soc. 69, 464-467.

Taylor, H. F. W. \& Howison, J. W. (1956). Clay Miner. 3, 98-111.

Trapote-Barreira, A., Cama, J. \& Soler, J. M. (2014). Phys. Chem. Earth Parts $A B C, \mathbf{7 0 - 7 1}, 17-31$.

Vandamme, M. \& Ulm, F. J. (2013). Cem. Concr. Res. 52, 38-52.

Viallis, H., Faucon, P., Petit, J. C. \& Nonat, A. (1999). J. Phys. Chem. $B, \mathbf{1 0 3}, 5212-5219$.

Viehland, D., Li, J. F., Yuan, L. J. \& Xu, Z. K. (1996). J. Am. Ceram. Soc. 79, 1731-1744.

Walker, C. S., Savage, D., Tyrer, M. \& Ragnarsdottir, K. V. (2007). Cem. Concr. Res. 37, 502-511.

Warren, B. E. (1941). Phys. Rev. 59, 693-698.

Yu, P., Kirkpatrick, R. J., Poe, B., McMillan, P. F. \& Cong, X. (1999). J. Am. Ceram. Soc. 82, 742-748.

Zhang, X., Chang, W., Zhang, T. \& Ong, C. K. (2000). J. Am. Ceram. Soc. 83, 2600-2604. 